\title{
When Indoles Meet Allene and its Derivatives
}

\author{
José M. Alonso, ${ }^{\star b}$ and María Paz Muñoz ${ }^{* a}$
}

\author{
[a] Dr M. P. Muñoz \\ School of Chemistry \\ University of East Anglia \\ Earlham Road, Norwich, NR4 7TJ, UK \\ E-mail: m.munoz-herranz@uea.ac.uk \\ [b] Dr J. M. Alonso \\ Departamento de Química Orgánica \\ Universidad Complutense de Madrid \\ Avda. Complutense s/n \\ 28040, Madrid, Spain \\ e-mail: josalo08@ucm.es
}

\begin{abstract}
The allene functional group and the indole ring have emerged as recurring building blocks in organic chemistry due to their diverse reactivity and straightforward preparation. In addition, indole biological properties and natural occurrence gives a remarkable added-value to newly-prepared indole-based structures. In the last decade, combination of allenes and indoles as co-reactants has revealed a fruitful reactivity allowing the synthesis of complex structures and the investigation on new mechanistic pathways, such as the challenging asymmetric nucleophilic addition using optically pure allenes as chirality transfer agents, the double nucleophilic addition through metal carbene intermediates, or novel hybrid catalysis in a bimetallic system. Herein we report a critical review into the wide and fascinating ways allenes and indoles can interact, and the structural diversity that can be therefore achieved.
\end{abstract}

\section{Introduction}

Alkaloids are of great interest for the scientific community due to the direct implications of these molecules in diverse disciplines such as organic synthesis, medicinal chemistry, biochemistry, pharmacology or medicine. Among the wide variety of alkaloid structures, indole-based systems are one of the most commonly reported, with an approximate number of 4100 different natural products, ${ }^{1}$ and an impressive number of diverse biological applications. ${ }^{2}$ In addition, the indole ring also shows a versatile reactivity, acting as base, as a nucleophile, or as an activated olefin in cycloaddition reactions. For all these reasons, indole has emerged as a recurring building block in organic synthesis, being the centre of numerous synthetic and methodological studies. ${ }^{3}$

On the other hand, allenes have gone through one of the most exciting journeys in organic chemistry, from scientific curiosities to common and useful building blocks, as they are currently considered. ${ }^{4}$ The complex reactivity of the allene moiety acting as electrophiles in metal-activated reactions, or as counterparts in cycloaddition processes, ${ }^{5}$ makes them ideal partners for indoles in chemical reactions. The strong nucleophilic character of indole has been largely explored in allene reactions both in racemic and asymmetric versions, and indole-allene cyclisation reactions can be employed to yield natural products core fragments in a straightforward manner. Thus, it is not a surprise to find a continuous and considerable amount of work dealing with the reactivity of allenes in the presence of indoles, showing a general trend of increasing complexity both for reaction mechanisms and final structures.

Herein, we present an overview of the reactivity of allenes and indoles, from the seminal intermolecular experiments, to the intramolecular reactions of indolylallenes and the most recent tandem processes, giving access to more complex skeletons through more sophisticated mechanistic pathways that are briefly mentioned in each example.

Although the reactivity of allenamides, alkoxyallenes and allenecarboxylates can be different from the reactivity of simple allenes, they all participate in interesting reactions with indoles giving important products and they all have been included in the review. The reactivity of the allenes with each chemical functionality has been grouped in the relevant sections.

Only reactions involving direct reactivity between the indole core and allenes or their derivatives are considered. Reactions in which allenes are generated in situ from alkyne derivatives, ${ }^{6}$ reactions involving indole-type compounds (such as oxindoles or isatins), ${ }^{7}$ indole-containing enyne cycloisomerisations, ${ }^{8}$ or other reactions in which indoles and allenes are present but do not interact directly ${ }^{9}$ have not been included.

\footnotetext{
José Miguel Alonso received his B. S. degree (1998) and his Ph. D. degree (2003) from Universidad Complutense de Madrid (Prof. Benito Alcaide and Prof. Pedro Almendros). Besides a diverse experience in the industry (environmental science, polymer chemistry), he worked as postdoctoral researcher at Universidade de Santiago de Compostela (Santiago de Compostela, Spain), Universidad Complutense de Madrid (Madrid, Spain),

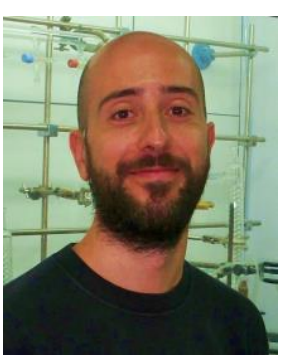
University of East Anglia (Norwich, UK) and IQOG-CSIC (Madrid, Spain). $\mathrm{He}$ is currently Assistant Professor in the Organic Department at Universidad Complutense (Madrid, Spain). His research interests include: allene and aryne chemistry, metal-promoted heterocyclizations, and homogeneous \& heterogeneous catalysis.
}

M. Paz Muñoz received her BSc (1999) and MSc (2001) in Organic Chemistry at the University Autónoma de Madrid, Spain, where she carried out her Ph. D. under the supervision of Prof. Antonio M. Echavarren (2004). Then, she joined the gorup of Prof. Guy C. Lloyd-Jones (University of Bristol, UK), where she held postitions of Research Assistant (LigBank Project), Postdoctoral Fellow (MEC) and Research Associate (EPSRC). In 2009, she joined the

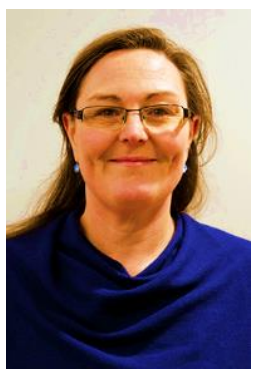
Instituto de Química Orgánica General (IQOG-CSIC) in Madrid, Spain with a prestigious Ramón y Cajal Award, where she started her independent research into the discovery of new platinum-catalysed reaction of allenes. In September 2011 she joined the University of East Anglia, Norwich, UK, 
where she was promoted to Senior Lecturer in 2017. Her main research interests are in the area of discovery and development of new organometallic reactions using single and bimetallic strategies, the use of physical-organic-inorganic chemistry to study the mechanisms involved, and the application to the synthesis of small organic and organometallic molecules with potential biological activity.

\section{Intermolecular reactions}

\subsection{Cycloadditions}

Intermolecular cycloaddition reactions using indoles and allenes have been reported for the synthesis of 4,5 and 6-membered rings $b$-fused to the indole skeleton. In all cases, activation of the allene and the indole by gold or phosphine is needed for the transformation to occur. Although mechanistic insights point that true concerted processes are unlikely, they can be classified as formal [2+2], [3+2], or [4+2] cycloadditions, respectively. These reactions are dominated by allenamides and allenecarboxylates but no examples with simple allenes have been reported.

For example, Bandini used the formal gold-catalysed [2+2] cycloaddition between indoles $\mathbf{1}$ and allenamides 2 for the synthesis of cyclobuta[b]indoles, a missing scaffold among the family of fused-[b]indoles, never achieved through any other methodology (Scheme 1). ${ }^{10}$ The strategy employed is based on the metal activation of the allenamide 2 , and the use of EWG on the indolic nitrogen to enhance the electrophilicity of the iminium carbon in intermediate 4, facilitating the ring closing step to yield the strained cyclobutane motif in $\mathbf{3}$ (Scheme 1). The reaction also works with aryloxyallenes, and the use of chiral phosphines allowed the enantioselective cycloaddition with up to $99 \%$ ee.

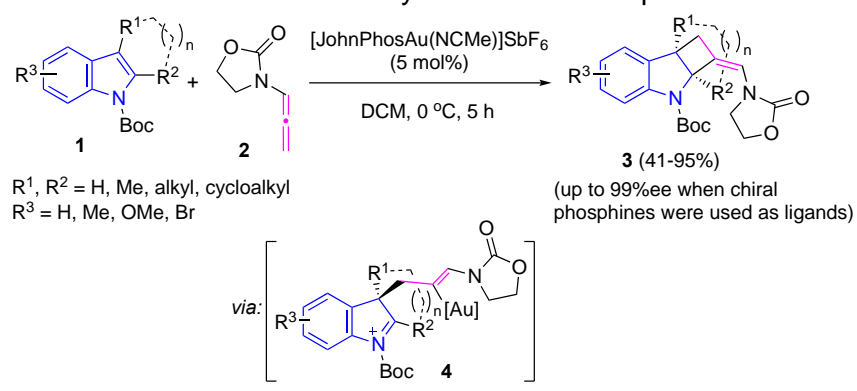

Scheme 1. Au-catalysed [2+2] allene-indole cycloaddition

Formal [4+2] cycloaddition of indoles and allenamides has been reported by Pirovano \& Rossi to generate the tetrahydrocarbazole motif. The gold-catalysed reaction of 2-vinyl indoles 5 with $\mathrm{N}$ allenamides 6 provided compounds 7 via cyclisation of a vinyl-Au intermediate $\mathbf{8}$, formed by addition of the indole to the allene through the $\mathrm{C} 3$ position (Scheme 2a). ${ }^{11 \mathrm{a}}$ In a more recent work from the same research group, the enantiomeric version of this transformation provided optically pure adducts 7 exhibiting up to 97\% ee. Also, alternative C3-tethered vinyl indoles 9 were submitted to enantiopure gold catalytic conditions to yield the [4+2] adducts 10a through an analogous reaction mechanism (Scheme $2 \mathrm{~b}$, top right). ${ }^{11 \mathrm{~b}}$ Interestingly, the enantioselective goldcatalysed [4+2] versus [2+2] cycloaddition of 3-styrylindoles with $\mathrm{N}$-allenamides 6 has also been reported by Xia \& Zhang using phosphoramidite ligands. ${ }^{12}$ The different outcome was attributed to the electronic nature of the $\mathrm{N}$-substituent of the indole. Electron withdrawing groups $\left(\mathrm{CO}_{2} \mathrm{Et}, \mathrm{Ts}, \mathrm{Ac}\right)$ would favour the [4+2] process to give 10b in up to $14: 1 \mathrm{Z}: \mathrm{E}$ and $97 \%$ ee (Scheme $2 \mathrm{~b}$, bottom right), while electron donating groups (alkyl, Bn, allyl) favoured the [2+2] process to give cyclobutanes 11 up to $96 \%$ ee (Scheme 2b left). This [2+2] cycloaddition was further expanded by the same group. ${ }^{13}$

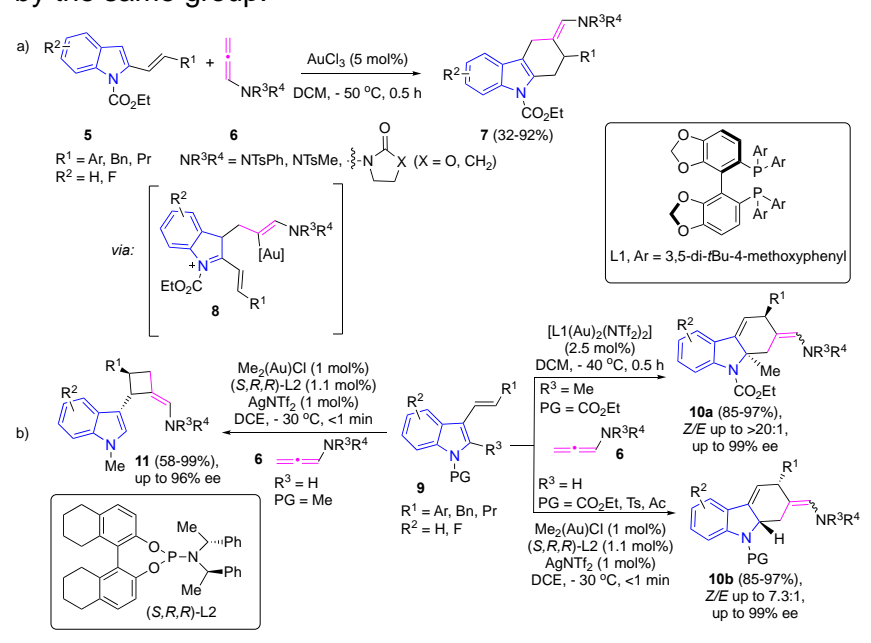

Scheme 2. Au-catalysed [4+2] allene-indole cycloaddition

Different research groups have recently contributed to the phosphine-catalysed de-aromative reaction of 3-nitroindoles with allenoates, to yield the cyclopenta[b]indoline core through a formal $[3+2]$ annulation process. ${ }^{14} \mathrm{Shi}^{14 \mathrm{a}}$ and $\mathrm{Ye}^{14 \mathrm{~b}}$ have independently described the reaction of differently substituted $\mathrm{N}$ protected 3-nitroindoles 12 with diverse terminal allene esters 13a providing tricyclic adducts $\mathbf{1 4 a}$ as single diastereomers under similar reaction conditions (Scheme 3 , path a). Both groups reported preliminary attempts towards the enantioselective version achieving moderate enantiomeric excesses $(62$ and $52 \%$ ee). In a similar approach, de Paolis \& Chataigner ${ }^{14 c}$ reported the reaction with substituted allenoate $13 \mathrm{~b}$ to generate cyclopenta[b]indolines $14 \mathrm{~b}$ exhibiting up to $3: 1 \mathrm{dr}$ (Scheme 3, path b). Enantiopure phosphines 15 and $\mathbf{1 6}$ have been respectively selected as chiral ligands by Zhang ${ }^{14 \mathrm{e}}$ and $\mathrm{Yu}^{14 f}$ in two simultaneous approaches to the asymmetric formal [3+2] cycloaddition of 3-nitroindoles 12 and allenoates 13a (Scheme 3, paths $\mathrm{c}$ and d). Enantioselectivities up to $95 \%$ ee and $99 \%$ ee were respectively achieved. The key for the reactions to occur is the activation of electron-deficient allenes by nucleophilic attack of the phosphine on the central carbon of the allene followed by indole addition to generate intermediate 17, that undergoes the de-aromative cyclisation with the indole (Scheme 3). 


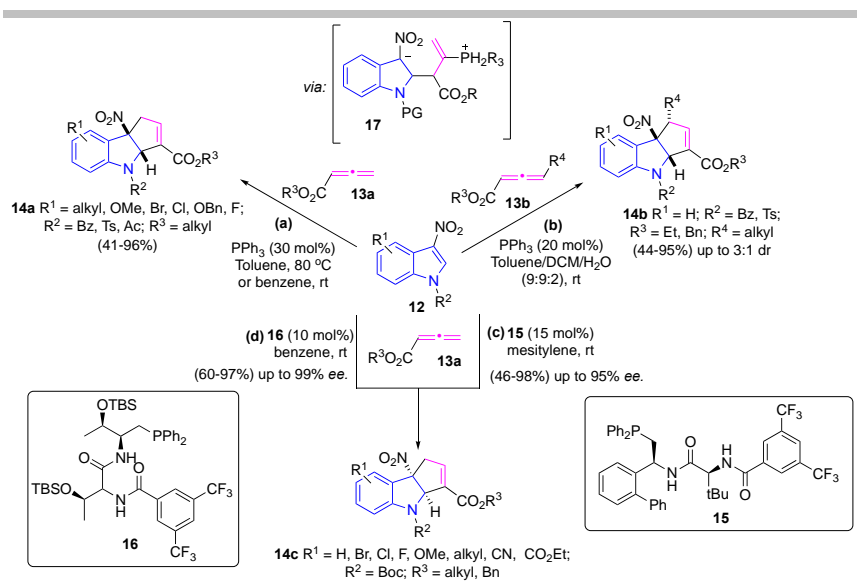

Scheme 3. Phosphine-catalysed [3+2] allene-indole cycloadditions

Other [3+2] cycloadditions have been reported using substituted indole precursors and allenes in which the reaction occurs on the extra functionalities of the indole without disrupting the indole core. ${ }^{15}$

\subsection{Nucleophilic addition of indoles to allenes}

2.2.1. Indole as C3-nucleophile. The strongest nucleophilic character of the C3 position in the indole ring has allowed numerous investigations on the synthesis of 3-substituted indoles. Widenhoefer reported a seminal approach towards the use of indoles $\mathbf{1 8}$ as C3-nucleophiles in additions to simple allenes $\mathbf{1 9}$ catalysed by $\mathrm{NHC}$-gold(I) complexes. ${ }^{16}$ The reaction was proposed to occur via vinyl-gold intermediates 21 (similar to $\mathbf{4}$ and 8 in Schemes 1 and 2), formed by $\pi$-activation of the allene by gold and selective nucleophilic addition of the indole towards the terminal (or less substituted) allenic carbon, yielding E-3-allylindoles $\mathbf{2 0}$ as single isomers in modest to good yields (Scheme 4).

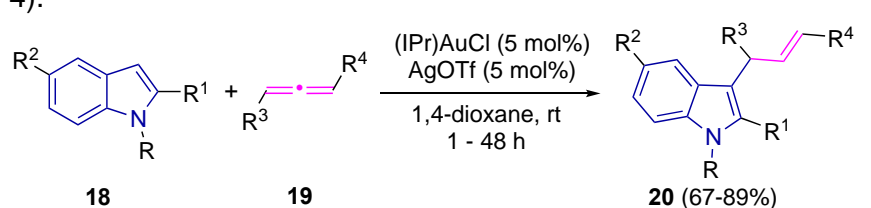

$\mathrm{R}, \mathrm{R}^{1}=\mathrm{H}, \mathrm{Me}$ $\mathrm{R}^{3}, \mathrm{R}^{4}=$ alkyl, $\mathrm{Ph},-\mathrm{CH}_{2} \mathrm{CH}\left(\mathrm{CO}_{2} \mathrm{Et}\right)_{2}$ $\mathrm{R}^{2}=\mathrm{H}, \mathrm{Me}, \mathrm{Cl}$

$$
\text { via: }
$$

Scheme 4. Au-catalysed nucleophilic addition of indoles onto allenes

This methodology has aroused the interest of different research groups in order to achieve the asymmetric version employing enantiomerically pure allenes as chirality transfer agents. In these reactions, racemisation normally occurs under gold-catalysed reaction conditions, probably due to the equilibrium between $\pi$ and $\sigma$-gold intermediates (22 and 23, Scheme 5a). In this context, Che reported the use of chiral allenes 22a bearing bulky aromatic substituents, leading only to $5 \%$ ee in the best of the cases (Scheme $5 b) .{ }^{17}$ The use of binuclear gold complexes with chiral phosphines and racemic allenes, gave moderate enantioselectivities up to $63 \%$ ee. Lee's research group eventually found that a combination of bulky and non-aromatic substituents in the allene system $\mathbf{2 2 b}$, in a way to destabilise $\sigma$ gold carbocations 23, dramatically increased the enantiomeric excess up to $98 \%$ in final substituted indoles $24 \mathrm{~b}$ (Scheme $5 \mathrm{c}$ ). ${ }^{18}$

a)

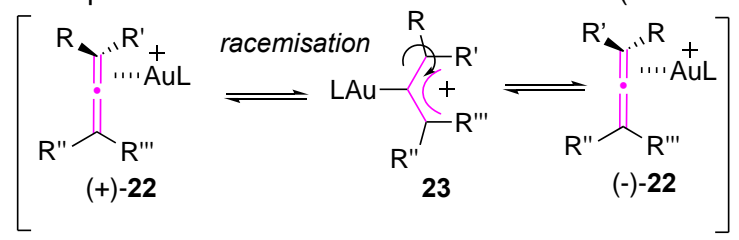

b)<smiles></smiles>

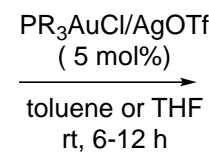

22a $(98 \% e e)$<smiles>Cn1cc(C(/C=C/c2ccccc2)c2ccccc2)c2ccccc21</smiles>

24a $(0-5 \%$ ee $)$<smiles>[R]C/C=C\C([R1])c1cn(C)c2ccccc12</smiles>

24b (up to 98:2 e.r.)

22b (98:2 to $99: 1$ e.r.)
$\mathrm{R}^{1}=\mathrm{Me}, \mathrm{Et}$

$\mathrm{R}^{2}=\mathrm{CN}, \mathrm{CO}_{2} \mathrm{Et}, \mathrm{OBn}$

Scheme 5. Chirality transfer in Au-catalysed intermolecular nucleophilic additions of indoles to allenes

A similar reaction was later developed by Ramana using alkoxyallenes 26 (Scheme 6). ${ }^{19}$ Depending on the alkoxy substituent, the reaction gives either E-3-allyl-indoles 27 , or alkylation of the indole in $\mathrm{C} 3$ with the pendant group of the allenyl ether 26 to yield indoles 28, when electron-rich allenyl ether derivatives were used. Similarly to the reaction with simple allenes, the reaction occurs to form $\mathbf{2 7}$ regioselectively by attack of the indole to the terminal carbon of the alkoxyallene.

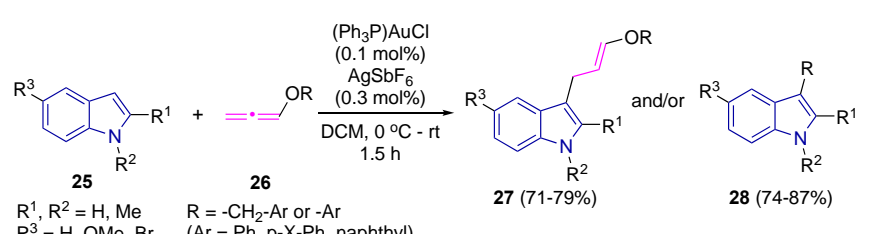

$\begin{array}{ll}\mathrm{R}^{3}=\mathrm{H}, \mathrm{OMe}, \mathrm{Br} & (\mathrm{Ar}=\mathrm{Ph}, \mathrm{p}-\mathrm{X}-\mathrm{Ph}, \text { naphthyl) }\end{array}$

Scheme 6. Au-catalysed nucleophilic addition of indoles onto alkoxyallenes

The reaction of indoles $\mathbf{2 9}$ with allenamides $\mathbf{3 0}$ has also been reported in the absence of catalysts to give $E$-enamide derivatives 31, again with regiochemical preference for the nucleophilic C3 attack by the indole into the terminal carbon of the allene (Scheme 7a). ${ }^{20}$ The presence of the $-\mathrm{NSO}_{2}$ group and its interaction with the distal double bond of the allene lowers the energy of the LUMO, which makes the double bond an excellent acceptor able to react with the nucleophile in the absence of catalyst. The reaction was later extended to the generation of iodo-derivatives 32 by addition of $\mathrm{N}$-iodosuccinimide (NIS), capable of reacting with the allene to form an iodiranium intermediate $\mathbf{3 3}$, that reacts with the indole in a 1,4-addition reaction (Scheme 7b). ${ }^{21}$ 


$$
\text { a) }
$$

Scheme 7. Reaction of allenamides and indoles in absence of metal catalyst

Allenamides and alkoxyallenes have been extensively explored by Bandini in the gold-catalysed de-aromatisation of 2,3disubstituted indoles for the synthesis of indolenine cores, common motifs in natural products. ${ }^{22}$ The reaction using 2,3disubstituted indoles $34(P G=H)$ and different allenamides 35a and alkoxyallenes $35 b^{10 c}$ gave the best results in the presence of cationic gold-phosphite complexes for the formation of substituted indolenines $\mathbf{3 6}$ by nucleophilic attack of the C3-indole into the gold-activated allenamides (Scheme 8a). When an electron withdrawing group is present in the nitrogen $(P G=\mathrm{Boc}, \mathrm{Cbz}$ ), protodeauration is not possible and intramolecular $\mathrm{C}-\mathrm{C}$ bond formation between the keto-imine and alkenyl-gold in the key intermediate (see 4 in Scheme 1) gives cyclobutene derivates 3 (Scheme 8a), as described in Scheme 1. Interestingly, the reaction can also be catalysed by chiral Brønsted acids 37 via iminium ion intermediates, which allowed the chemo- regio- and stereoselective de-aromatisation of 2,3-disubstituted indoles 34 with enantioselectivities up to $92 \%$ ee (Scheme $8 \mathrm{~b}$ ). The group performed in depth mechanistic investigations, including NMR studies to assess the role of the counterion in the gold catalysed reaction ${ }^{23}$ and theoretical calculations and ESI-MS analysis for the Brønsted acid catalysed one. ${ }^{24}$

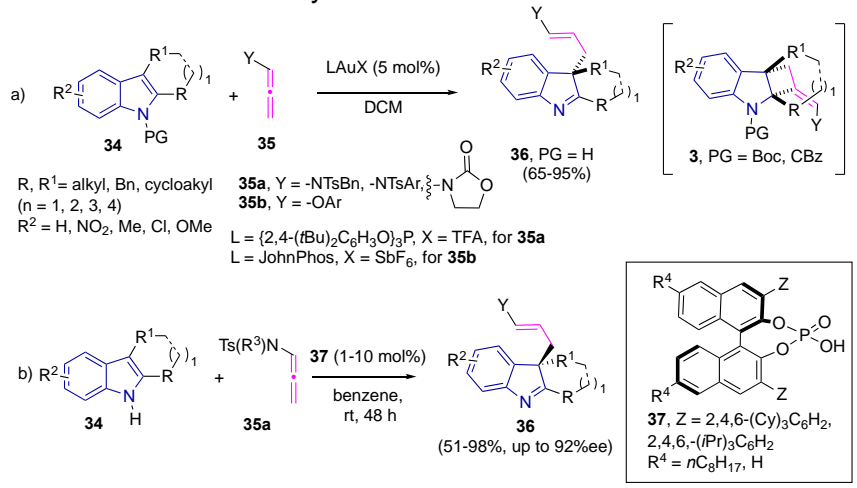

Scheme 8. Reaction of 2,3-disubstituted indoles with allenamides

Interestingly, the $\mathrm{Pd}(0)$-catalysed reaction of similar tetrahydrocyclopenta[b]indoles $\mathbf{3 8 a}$ in the presence of 2,3-allenyl carbonates 39 and trapping agents (acyl chlorides), gave enamine derivatives $\mathbf{4 1}$ in which the allene was still present in the final structure (Scheme 9a). ${ }^{25}$ The reaction was carried out in the presence of base, being BSA ( $\mathrm{N}, \mathrm{O}$-bis-(trimethylsilyl)-acetamide) the one that gave best results, and 1 equivalent of $\mathrm{Et}_{3} \mathrm{~B}$ to activate the indole through $\mathrm{N}-\mathrm{B}$ bond formation. The reaction was proposed to go through oxidative addition of $\operatorname{Pd}(0)$ to the allenyl carbonate, giving intermediate $\mathbf{4 0}$ after release of $\mathrm{CO}_{2}$. Then, C3- indole attack to the terminal position in $\mathbf{4 0}$ would provide the new allene moiety in imine intermediate 41a, which was further trapped with acyl chloride to yield indolines 42. The transformation was later expanded to less-strained 2,3-disubstituted indoles 38 in the absence of the trapping agents to obtain indoline-type products $\mathbf{4 1}$ via $\mathrm{N}$-indolyltriethylborates $\mathbf{4 3}$ (Scheme $9 \mathrm{~b}$ ). ${ }^{26}$

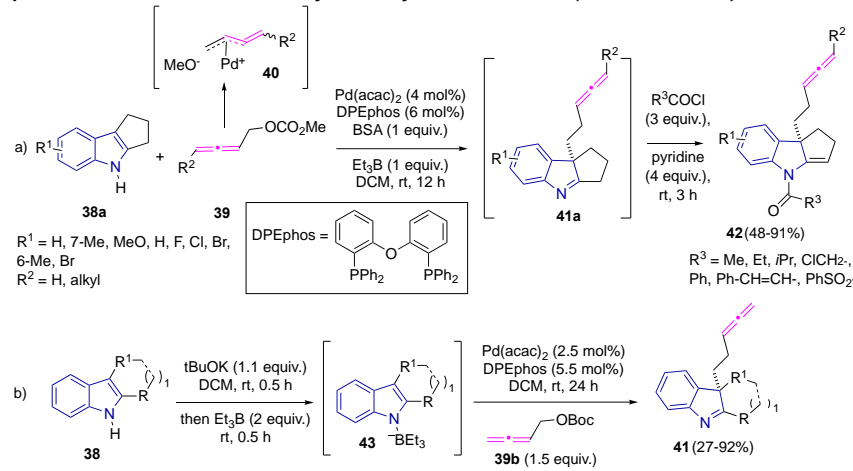

Scheme 9. Pd-catalysed reaction of 2,3-disubstituted indoles with allenyl carbonates

In the context of increasing molecular complexity, the addition of two indole nucleophiles onto allenes has been described to generate the bis(indolyl)methane scaffold, a recurrent motif in pharmacology and medicinal chemistry. ${ }^{27}$ Two different approaches have been reported. Ma described a double nucleophilic addition of indoles 44 onto 1,2-allenic ketones 45 catalysed by $\mathrm{Sc}(\mathrm{OTf})_{3}$, where the selective indole addition occurs at the central allenic carbon to give $\beta, \beta$-bis(indolyl)ketones 46 (Scheme 10a). ${ }^{28}$ Addition of 1 equivalent of the allene allows the stepwise formation of $\beta$-indolyl- $\alpha, \beta$-unsaturated $(E)$-enones 47 as direct intermediates in the bisindolylation reaction.

An alternative reaction mechanism was revealed by Muñoz in the platinum-catalysed reaction of indoles $\mathbf{4 8}$ with simple allenes $\mathbf{4 9}$. In this case, the attack of the two indoles occurs at the terminal carbon of the allene with the involvement of platinum carbene intermediates $\mathbf{5 1}$ to give bis(indolyl)methane derivatives $\mathbf{5 0}$ (Scheme 10b). ${ }^{29}$

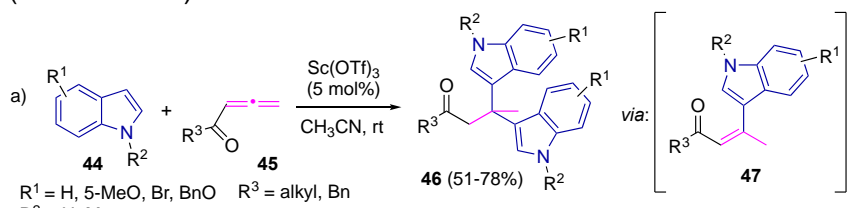
$\mathrm{R}^{1}=\mathrm{H}, 5-\mathrm{M}$
$\mathrm{R}^{2}=\mathrm{H}, \mathrm{Me}$

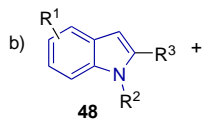

$\mathrm{R}^{1}=\mathrm{Br}, \mathrm{OH}$, alky $\mathrm{R}^{2}=\mathrm{H}, \mathrm{Me}, \mathrm{Bn}$ $\mathrm{R}^{3}=\mathrm{H}, \mathrm{Me}$

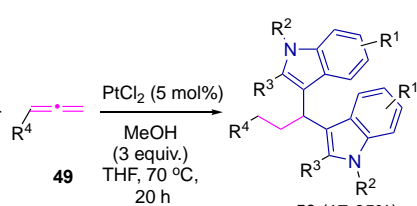

$50(17-95 \%)$

$\mathrm{R}^{4}=\mathrm{Cy}, \mathrm{Ph}, \mathrm{CH}_{2}$ Phthalimide, $\mathrm{CH}_{2} \mathrm{CH}\left(\mathrm{CO}_{2} \mathrm{Et}\right)_{2}$, alkyl

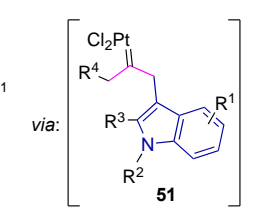

Scheme 10. Bis(indolyl)methane synthesis through Sc- and Pt-catalysis

Indole-based trimer species $\mathbf{5 3}$ were reported by Barluenga in the gold-catalysed reaction of C2-substituted $\mathrm{N}$-indolylallenes $\mathbf{5 2}$ when the reactions were carried out under careful control of time and concentration (Scheme 11). ${ }^{30}$ The reaction is proposed to undergo sequential activation of the allene and trapping by the indole through the more nucleophilic C3-position to give the macrocycle $\mathbf{5 3}$ after formation of the linear trimer and cyclisation. 
The stepwise nature of the reaction was supported by isolation of the dimer and small amounts of the acyclic trimer.

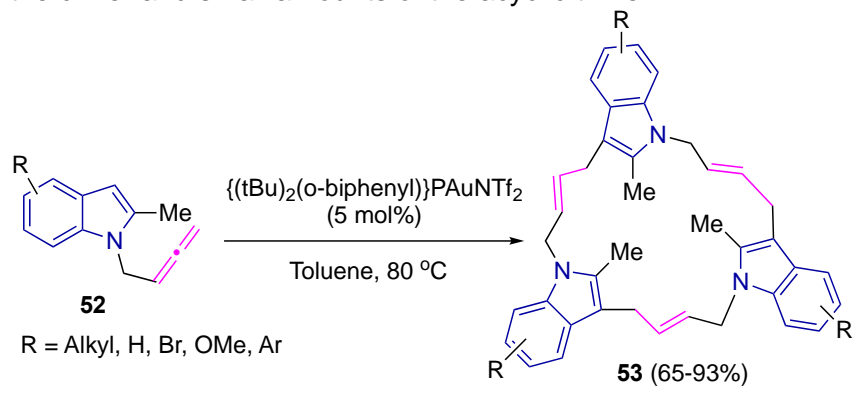

Scheme 11. Au-catalysed trimerisation of 2-Me- $N$-indolylallenes

2.2.2. Indole as C2-nucleophile. Different groups have attempted the nucleophilic addition of indoles to allenes through the less reactive $\mathrm{C} 2$ position. A common strategy is to block the C3 position with a substituent. In some of the examples described in the previous section, addition to the $\mathrm{C} 2$ position occurs when the $\mathrm{C} 3$ is blocked by a substituent. ${ }^{18,29,30}$

A different strategy was employed by Rueping, based on the use of heteroaromatic substituents in the $N$-position of the indole, like in precursors 54 (Scheme 12a), in order to activate the nucleophilicity of the $\mathrm{C} 2$ carbon through metal coordination (58) for reaction with allenoates $55 .{ }^{31} \mathrm{C}-\mathrm{C}$ bond formation occurs with the central carbon of the allenoate. Interestingly, it was reported simultaneously by Rueping ${ }^{31}$ and $\mathrm{Li} \&$ Wang $^{32}$ that when trisubstituted allenes are used in this reaction, the $\mathrm{C}-\mathrm{H}$ activation is followed by cascade Smiles rearrangement with heterocyclic group rearrangement and cyclisation to give pyrroloindilones $57 .{ }^{33}$ Alternatively, Ackermann described the use of cationic cobalt catalysts facilitating the reaction with alkyl-substituted allenes 60 . The expected change of the regioselectivity towards the terminal addition onto the allene systems allowed the preparation of alkenyl indoles 61 (Scheme 12b). ${ }^{34}$
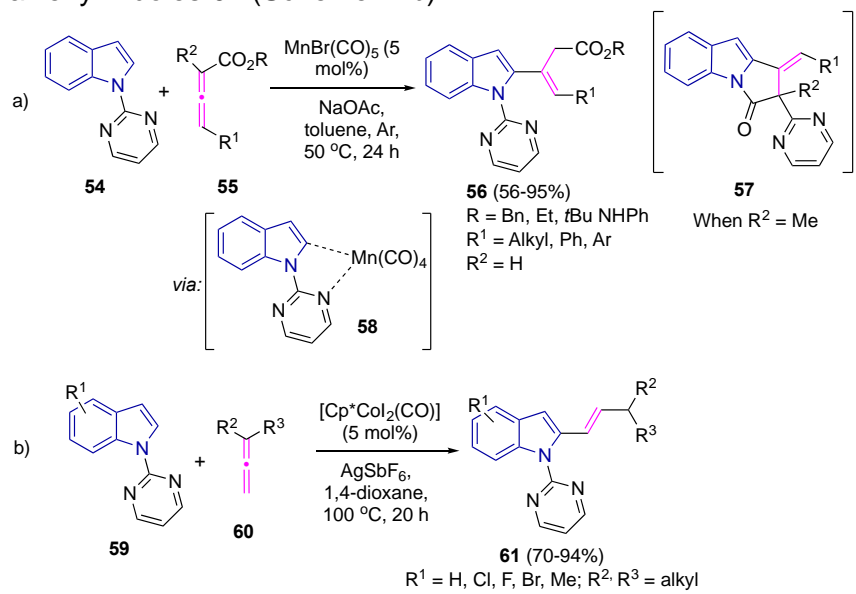

Scheme 12. Metal activation of the $C 2$ indole position, application to intermolecular nucleophilic addition to allenoates

2.2.3. Indole as $\mathbf{N}$-nucleophile. The aza-addition of indoles to allenes is not widely reported. However, Chen recently reported the base-promoted synthesis of functionalised $N$-arylindoles 64 by reaction of indoles 62 with two equivalents of allenic ketones 63 (Scheme 13). ${ }^{35}$ The reaction occurs via sequential double Michael addition of the deprotonated indole onto the central carbon of the allenic ketones followed by cyclisation of the intermediate $\mathbf{6 5}$ and loss of water for aromatisation.

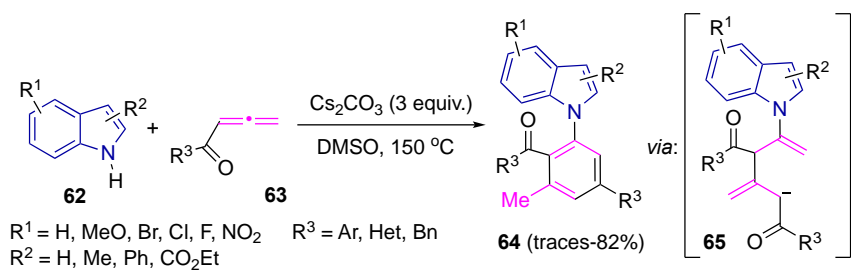

Scheme 13. Base-promoted benzannulation of 1,2-allenic ketones with indoles

Another example in which the nitrogen of the indole acts as the aza-nucleophile was described by Rhee. ${ }^{36}$ The group reported the palladium-catalysed asymmetric aza-addition of indoles 66 to alkoxyallenes 67, with a pending olefin (Scheme 14). The nucleophilic attack occurred at the more substituted end of the alkoxyallene. The subsequent ring closing metathesis reaction on product 68 led to an elegant flexible synthesis of $\mathrm{N}$ glycosylindoles 69 .

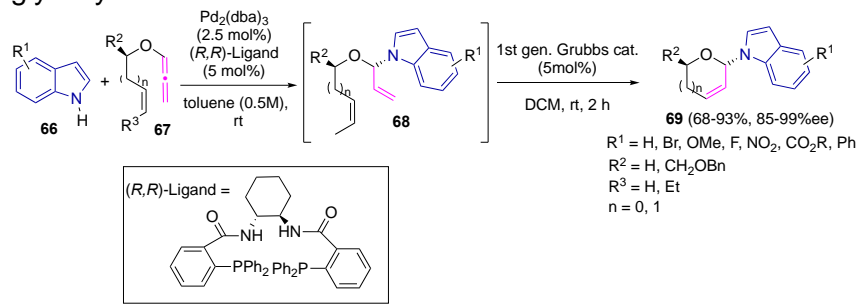

Scheme 14. Pd-catalysed asymmetric addition of indoles to alkoxyallenes

\section{Intramolecular reactions}

During the last decade, many groups have started to explore both the preparation, ${ }^{37}$ and reactivity of indolylallenes with different connectivity between the allene and the indole. The extended and complex chemistry developed so far from indolylallenes can be organised in intramolecular formal cycloadditions, nucleophilic additions from $\mathrm{C} 3-, \mathrm{C} 2-$ and $\mathrm{N}$-indoles as nucleophile. The divergent reactivity that similar substrates exhibit under different conditions is the most fascinating feature of this chemistry.

\subsection{Cycloadditions}

Similar to the intermolecular reactions described in section 2.1, there are reports of formal intramolecular cycloadditions of indolylallenes with different connectivity. For example, Tang \& Shi have reported a stereo- and regioselective synthesis of indolefused polycycles from $\mathrm{N}$-indolylallenes 70 . The use of a platinum complex promoted a formal [3+2] cycloaddition towards diazabenzo[a]cyclopenta[cd]azulenes 71a as a single isomer in the newly formed all-carbon quaternary centre. Interestingly, gold catalysts bearing bulky ligands reverted the configuration of the new stereocentre yielding epimers $\mathbf{7 1 b}$. A complete change of the regioselectivity was achieved in the presence of carbene-gold catalysts, yielding tricyclic compounds 72 through an exo-type $[2+2]$ formal cycloaddition (Scheme 15). ${ }^{38}$ 


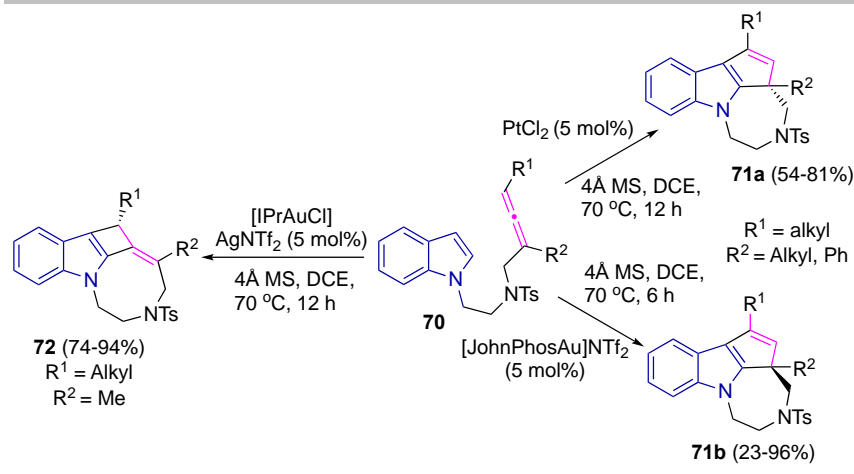

Scheme 15. Catalyst-dependent regio- and stereoselectivity in indolylallene cyclisation

In a similar approach, the kinetic resolution reaction of tryptamine derivative C3-indolylallenes $73 a$ in the presence of enantiopure gold catalysts has been reported by Shi to give enantioenriched polycyclic indolines $\mathbf{7 4}$ possessing four stereogenic centres, including an all-carbon quaternary centre. ${ }^{39}$ The transformation is proposed to occur through spirocyclic intermediate $\mathbf{7 5}$, generated from the nucleophilic attack of the C3 carbon atom of the indole moiety to the inner allenic carbon. Further carbon-carbon coupling would provide the experimentally observed systems $\mathbf{7 4 a}$ exhibiting high enantiomeric excesses, together with enantioenriched tryptamine allenes $(R)$-73a (Scheme 16a). This methodology was further extended using bis-(indoly-3-yl)-allenes 73b $\left(R^{3}=\right.$ indole $)$ as starting materials to give $74 b$ analogues (Scheme 16b). ${ }^{40}$ The same compounds $73 \mathrm{~b}$, in the presence of platinum catalysts gave the fused spiroindoline derivatives 76 in 3:1 d.r., again highlighting the versatility of these systems under different reaction conditions.

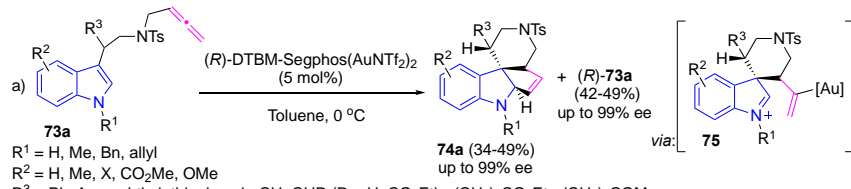

$\mathrm{R}^{3}=\mathrm{Ph}, \mathrm{Ar}$, naphthyl, thiophenyl, $-\mathrm{CH}=\mathrm{CHR}\left(\mathrm{R}=\mathrm{H}, \mathrm{CO}_{2} \mathrm{Et}\right),-\left(\mathrm{CH}_{2}\right)_{2} \mathrm{CO}_{2} \mathrm{Et},-\left(\mathrm{CH}_{2}\right)_{2} \mathrm{COMe}$

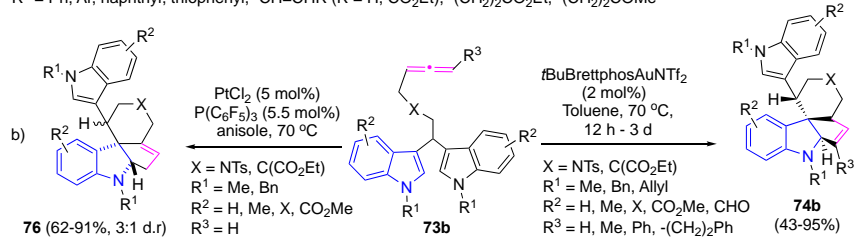

Scheme 16. Metal-catalysed reaction of tryptamine allene derivatives

In a different strategy, the photochemical intramolecular [2+2] cycloaddition of $\mathrm{N}$-indolylallenes $\mathbf{7 7}$ has been recently reported with 3',4'-dimethoxyacetophenone as sensitiser, to give an indole containing all-cis-fused methylenecyclobutane core $\mathbf{7 8}$ in a highly stereoselective manner (Scheme 17). ${ }^{41 a}$ Small amounts of alkyne products 79 were also obtained in the reaction via 1,5-hydrogen transfer on biradical intermediates.

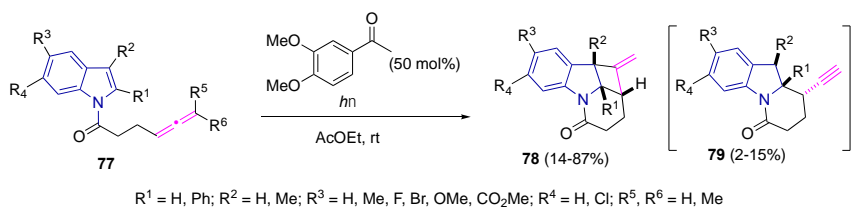


Ma has further exploited this reactivity in the presence of gold(I) in the reaction with methoxypropadiene derivatives $\mathbf{8 8 b}$ for the synthesis on naturally occurring 2-alkoxylated carbazole structure 89b (Scheme 20b)..$^{50}$ The platinum-catalysed reaction was also expanded to polysubstituted allenes 88c (Scheme 20c). ${ }^{51}$ The reaction is proposed to go via platinum carbene intermediates in which favoured aryl migration of one of the terminal substituents $\left(R^{3}\right)$ leads to the synthesis of carbazoles $89 \mathrm{c}$ with multiple substitution around the aromatic ring. ${ }^{52}$ a)<smiles>[R9]C=C([R])C(O)c1cc2ccccc2n1[Tl]</smiles>

88a

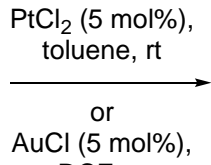

DCE, rt<smiles>[R]c1cc([R])c2c3ccccc3n([Tl])c2c1</smiles>

89a $(58-92 \%)$
$\mathrm{R}^{1}=\mathrm{H}$, alkyl, Bn; $\mathrm{R}^{2}=\mathrm{H}$, alkyl, Ph; $\mathrm{R}^{3}=\mathrm{H}$, alkyl, Bn, Ph b)<smiles>COC(=[IH])C(O)c1cc2ccccc2n1Cc1ccccc1</smiles>

88b<smiles></smiles>

$89 b(81 \%)$<smiles>[R]C([R])=C=C([R])C([R])(O)c1cc2cbccc2n1CC</smiles>

88c $\underset{\text { toluene, rt }}{\stackrel{\mathrm{PtCl}_{2}(5 \mathrm{~mol} \%)}{\longrightarrow}}$<smiles>[R]c1[R]([H])c2[pH][13cH]ccc3c2c(c([R7])c1[R])n3CC</smiles>

89c $(61-87 \%)$
$R^{1}, R^{2}=H, M e ; R^{3}=$ alkyl, $A r ; R^{4}=A r ; R^{5}=H, M e, O M e$

Scheme 20. Synthesis of carbazoles from indolylallenols

Alcaide \& Almendros have contributed immensely to the indolylallene reactivity during the last years. Recent efforts have been reported to gain structural complexity from a sole and readily available starting material in an atom economic manner. Thus, a divergent reactivity pattern has been unravelled from 3-iodoindole derivatives $\mathbf{9 0}$. Reaction of $\mathbf{9 0}$ in the presence of the bimetallic pair $\mathrm{Pd}\left(\mathrm{PPh}_{3}\right)_{2} \mathrm{Cl}_{2} / \mathrm{Cul}$ yielded iodocarbazoles 91 as sole reaction products, through an unprecedented 1,3-intramolecular migration of iodine ${ }^{53}$ Interestingly, the presence of a base in the reaction media under similar experimental conditions allowed a switch in the reaction pathway, yielding cyclopentenones 92 through an intramolecular Heck-type process (Scheme 21)..${ }^{54}$

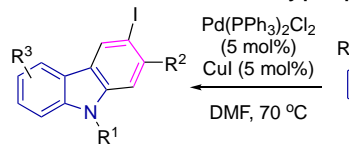

91 (41-69\%)

$\mathrm{R}^{2}=\mathrm{H}$, alkyl, $\mathrm{Ph} ; \mathrm{R}^{3}=\mathrm{H}, \mathrm{OR}$

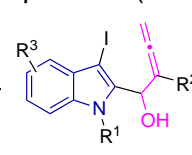

90
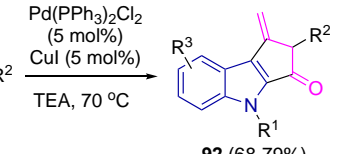

$92(68-79 \%)$ $\mathrm{R}^{3}=\mathrm{H}, \mathrm{Cl}, \mathrm{OMe}$, alkyl
Scheme 21. Chemical diversity from indolylallenols

The same group has also reported the synthesis of 7- and 8membered rings fused to the indole skeleton through 7-exo-trig and 8-endo-trig gold-catalysed processes. In this work, two biologically attractive motifs, the indole and the $\beta$-lactam ring are combined in structures 93 to generate polycycles 94 exhibiting high structural complexity (Scheme 22). ${ }^{55}$

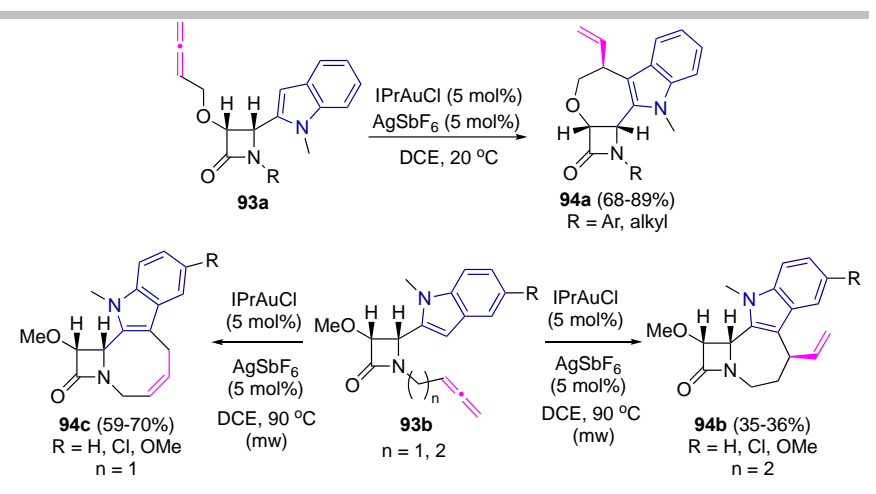

Scheme 22. $\beta$-Lactamic indolylallenes in Au-catalysed cyclisations

3.2.2. Indole as C2-nucleophile. The less nucleophilic position $\mathrm{C} 2$ in the indole ring has been involved mainly in carbocyclisation reactions of $\mathrm{N}$-indolylallenes. For example, reaction of $\mathrm{N}$ indolylallenes 95a reported by Barluenga (see Scheme 11), ${ }^{30}$ in which the C2 position is available to react as nucleophile in an intramolecular way through a 6-endo-trig process, generates tricyclic systems 96 , a common scaffold found in many natural products such as the Vinca alkaloids (Scheme 23a). ${ }^{56}$

In a similar strategy, Toste reported the use of gold catalysis in the key ring-closing step in $\mathrm{N}$-indolylallene 97 , to yield the tricycle 98 through a 5-exo-trig process towards the synthesis of natural product finderole $\mathrm{B}$, an important antimalarial agent isolated from plants of the Flindersia genus (Scheme 23b). ${ }^{57}$

The reaction of $N$-indolylallene precursors of type $95 \mathrm{~b}$ has also been described with NIS in the absence of metals and under mild conditions to give similar dihydropyrido[1,2-a]indoles 99 in which the iodine atom is incorporated in the final skeleton (Scheme 23c). ${ }^{58}$

a)<smiles>C=CCn1ccc2c1=CC=C[R]C=2</smiles>
$\left\{\mathrm{P}(t-\mathrm{Bu})_{2}(\mathrm{o}\right.$-biphenyl $\left.)\right\}$ AuNTf $_{2}$
$(5 \mathrm{~mol} \%)$

$80^{\circ} \mathrm{C}$ $80^{\circ} \mathrm{C}$

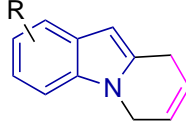

95a

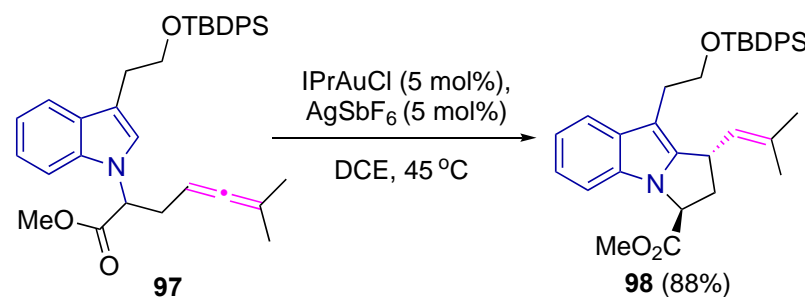

c)<smiles>[R]C([R])=C=C([R])Cn1cc(C)c2c[Z10]([H])ccc21</smiles>

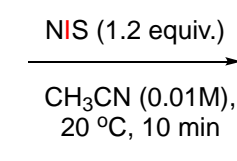

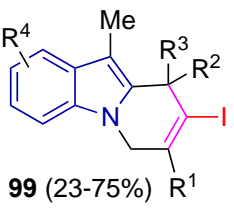

$R^{1}=H$, Me, Et; $R^{2}, R^{3}=$ alky; $R^{4}=H, F$, OMe

Scheme 23. Au-catalysed carbocyclisation on $\mathrm{N}$-indolylallenes

3.2.3. Indole as C2 vs C3 nucleophile. When C3-indolylallenes are used, competition between $\mathrm{C2}$ - and C3- nucleophilic addition normally happens, leading to indole $[b]$ fused systems or spirocyclic compounds respectively. In many cases, C-C bond formation from $\mathrm{C} 2$-indole takes place via initial C3-nucleophilic 
addition yielding the spirocyclic intermediate, and further rearrangement. In this section we will cover examples in which C3-indolylallenes act as C2 nucleophiles, along with C2 vs C3 competition.

Similar to examples described in section 3.2.1, carbazole-type molecules can be prepared from C3-indolylallenes under transition metal catalysis conditions. For example, gold-catalysed carbocyclisation of tryptamine-derived allenamides 100 with a 2atom chain linker, provided substituted tetrahydro-aza-carbazoles 101 in excellent yields and high enantioselectivity (Scheme 24a). ${ }^{59}$ Alternatively, if the C2-position is blocked, reaction of similar substrates 102a followed the intramolecular dearomatisation described by Bandini, to give $C(3)$ spiroindoleine compound 103 (Scheme 24b, left). ${ }^{22}$ In a similar approach, 2bromo precursors $102 \mathrm{~b}$ reacted under gold catalysis to yield the corresponding spirocyclic compound 104. The oxo-indole functionalization was observed after treatment with TFA (Scheme 24b, right). ${ }^{60}$ Interestingly, Breit has recently reported the enantioselective reaction of related allenes 105 in the presence of rhodium catalysts to give the tetrahydrocarbazole core 107 via formation of spirocycle intermediates $106^{61}$ that can also be trapped in situ with a reductant to give functionalised vinylic spiroindoles 108 (Scheme 24c). ${ }^{62}$

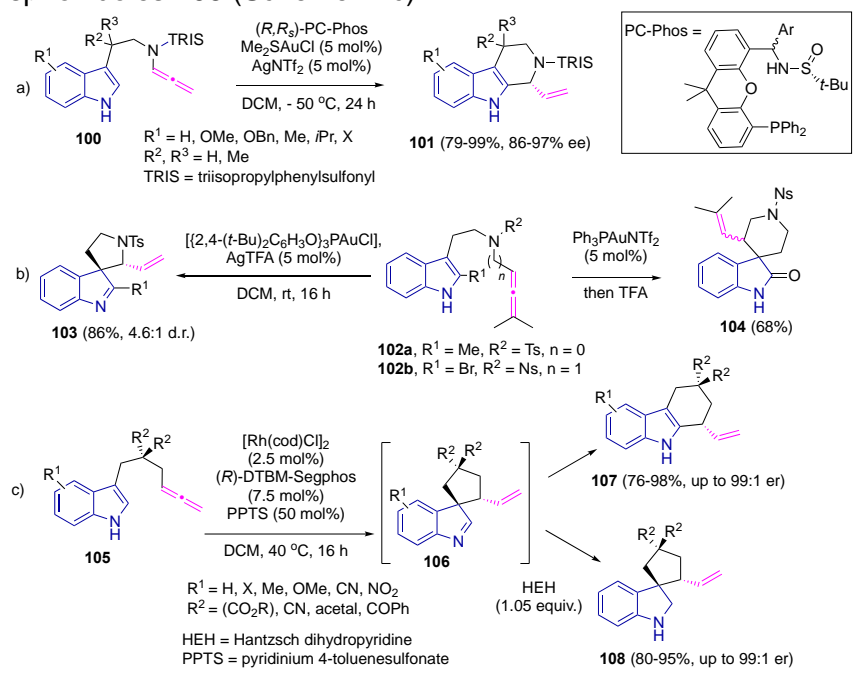

Scheme 24. Metal-catalysed reaction of C3-indolylallenes with 2 C-chain linker

Cationic gold species have promoted the dihydrocarbazole synthesis from compounds 109, in which indole and allene are separated by one carbon, unravelling a complex reaction mechanism where C3 vs C2 indole nucleophilicity competes yielding a mixture of carbocyclisation products 110 and rearrangement products $\mathbf{1 1 1}$ trough spirocyclic intermediates (112, Scheme 25a). ${ }^{63}$ Similarly, the reaction of indolylallenes 114a, made by Friedel-Crafts reaction of allenols 113 and indoles, in the presence of gold catalysis at low temperature and an oxidant, gave fully aromatised carbazoles $\mathbf{1 1 5}$ as sole reaction products (Scheme 25b). ${ }^{64}$ Recently, Luna \& Almendros described the solvent and temperature-dependent regioselective reaction of indolylallenes $114 \mathrm{~b}$ to give spirocycles 116 and carbazole-type compounds 117 and 118 under heterogenous catalysis. ${ }^{65}$ Treatment of indollylallenes 114b with AgNPs (1 wt\%) on polar solvents and moderate temperatures allowed the isolation of spirocyclic compounds 116 (Scheme 25c, left), plausible intermediate in the rearrangement transformation towards tricyclic structures 117 and 118 that are obtained in less polar solvents (Scheme 25c, right).

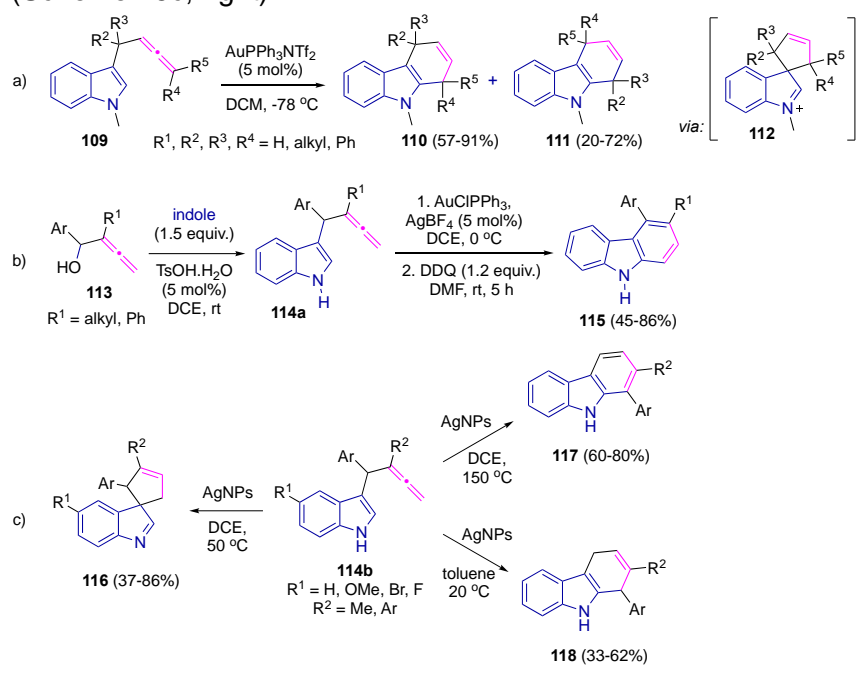

Scheme 25. Divergent reactivity from C3-indolylallenes with $1 \mathrm{C}$-chain linker

In an alternative approach, the use of 3-indolylallenoles $\mathbf{1 1 9}$ has also been reported to be useful for the carbazole scaffold preparation in compounds 120 (Scheme 26a, left). In addition, allenols 119 along with the corresponding 3-indolylallenones 122 have shown an added applicability for the synthesis of dihydrofuryl and furyl derivatives 121 and 123, respectively, through oxycyclisation processes (Scheme $26 \mathrm{a}$ and $26 \mathrm{~b}$, right). ${ }^{66}$ The chemoselectivity observed for this transformation was reported to be tuneable by switching the electronic nature of the nitrogen substitution in the indole ring. Thus, deactivated allenols 119 selectively yielded oxycyclisation products, while deactivated allenones 122 underwent through Nazarov-type metal-catalysed carbocyclisation to yield cyclopentenones 124 along with oxycyclisation products 123 , illustrating the more complicated reactivity patterns when indoles are acting as $\mathrm{C} 2$ nucleophiles (Scheme 26a, right and 26b, left).

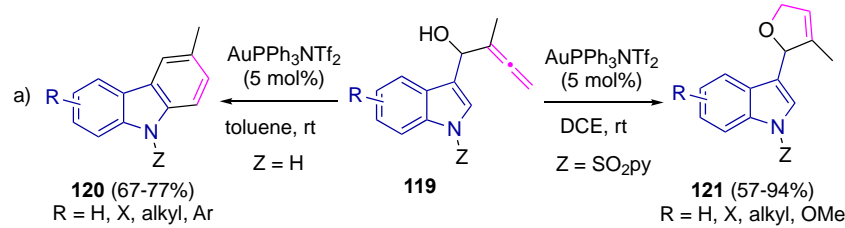

$$
\begin{aligned}
& 124(0-58 \%), R=\mathrm{H} \text {, alkyl, } \mathrm{Ar} \\
& 123(19-94 \%), \mathrm{R}=\mathrm{H}, \text { alkyl, } \mathrm{Ar}
\end{aligned}
$$

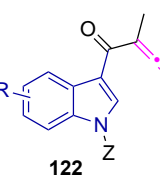

Scheme 26. Divergent reactivity from C3-indolylallenols and C3indolylallenones

Ma also reported the gold-catalysed reaction of indolylallenes in which an electron-deficient allene is directly bonded to the C3indole (125, Scheme 27). 67 The reaction gives dihydrocyclopenta[b]indole derivatives 126, analogues of the carbazole core. The presence of the electron withdrawing groups on both the allene and the indolic nitrogen was crucial for the observed reactivity. Computational studies have been recently 
disclosed in which the role of the gold complex counterion and solvent effects were investigated. ${ }^{68}$

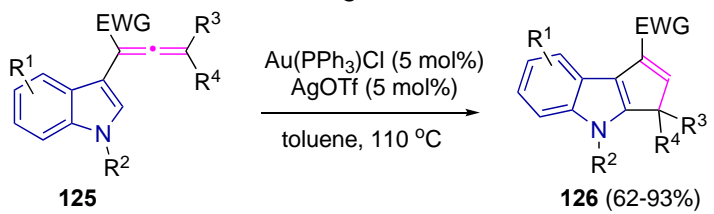

$\mathrm{R}^{1}=\mathrm{H}, \mathrm{Me}, \mathrm{OMe}, \mathrm{Cl}, \mathrm{Br}, \mathrm{F} ; \mathrm{R}^{2}=\mathrm{Ts}, \mathrm{CO}_{2} \mathrm{R}(\mathrm{R}=\mathrm{Me}, \mathrm{Ph}) ; \mathrm{R}^{3}, \mathrm{R}^{4}=$ Alkyl, cycloalkyl $\mathrm{EWG}=\mathrm{CO}_{2} \mathrm{Me}, \mathrm{Ph}, \mathrm{P}(\mathrm{O})(\mathrm{OEt})_{2}$

Scheme 27. Au-catalysed reaction of directly bonded C3-indolylallenes

3.2.4. Azacyclisation. Intramolecular reactions in indolylallenes involving the nitrogen as the nucleophile are scarce in comparison with the above mentioned $\mathrm{C} 3$ or $\mathrm{C} 2$ carbocyclisation reactions.

An example has been described in the palladium-catalysed hydroamination of C2-indolylallenamides 127 to give 3-vinylsubstituted imidazo[1,5-a]-indoles $128 .{ }^{69}$ In the presence of Arl or Arl and $\mathrm{CO}$ atmosphere, the carboamination and carbonylative amination can take place respectively, through $\pi$-allyl-palladium intermediates $129 \mathrm{~b}$, giving more substituted derivatives 130 in a tandem process (Scheme 28).

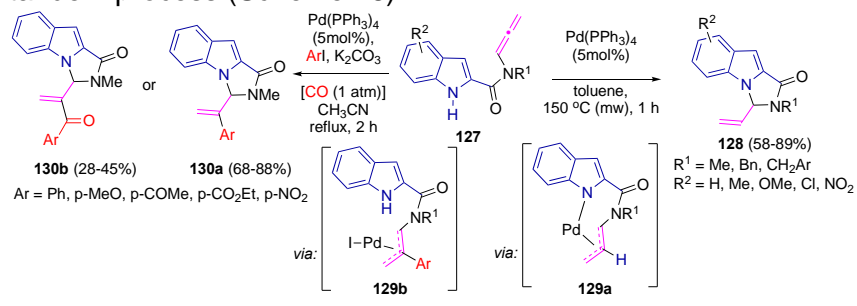

Scheme 28. Pd-catalysed hydroamination of C2-indolylallenes

\section{Tandem reactions}

The last years have started to witness an increasing sophistication in synthetic methodologies including allenes and indoles or indolylallenes, in order to gain access to more complex structures through more efficient and atom-economic procedures. In this section we have covered tandem and cascade processes involving inter- and intramolecular reactions between an allene, an indole and other components, also including double intramolecular processes of indolylallene derivatives and other components.

\subsection{Tandem intra-inter or inter-intramolecular reactions}

Reaction in which external components react with intermediates of cyclisation processes involving indolylallenes (as described in section 3) have been recently reported.

For example, Alcaide \& Almendros have described a tandem carbocyclisation/cross-coupling reaction of indolylallenoles 131 (see also Schemes 20 and 26) yielding differently substituted allylcarbazoles 133 in the presence of allylbromides $132,{ }^{49}$ or the pharmacologically attractive 1,4 -butadienyl carbazoles $135,{ }^{70}$ in the presence of $\beta$-acetoxyallenes 134, through chemo-, regioand stereospecific processes catalysed by $\mathrm{PdCl}_{2}$ through the common intermediate $\mathbf{1 3 6}$ formed by 6 -endo-trig carbopalladation of 131 (Scheme 29). ${ }^{71}$

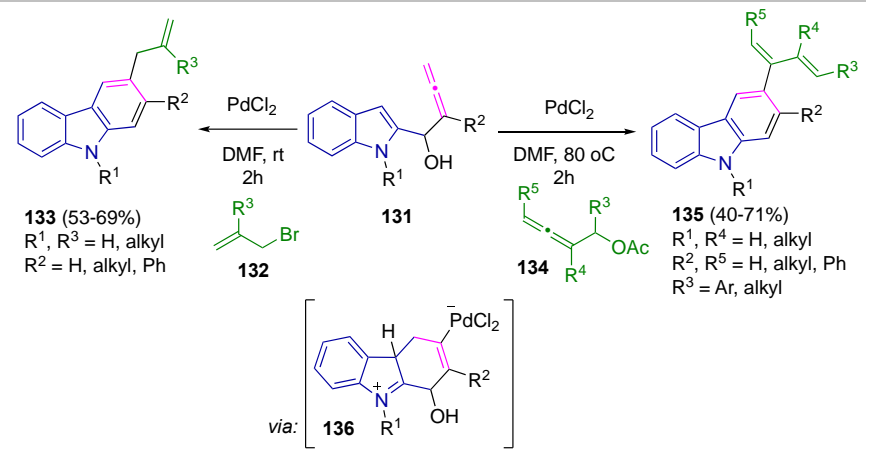

Scheme 29. Tandem Pd-catalysed carbocyclisation/allene-alkene and alleneallene cross-coupling reactions with $\mathrm{C} 2$-indolylallenols

The same group has also reported the synthesis of 2-allenyl-3,3difluoroindolines 138 from $N$-indolylallenes 137 by reaction with Selectfluor and iron catalysis through a dihydrofunctionalisation/aza-Claisen rearrangement. ${ }^{72}$ The corresponding fluorinated derivatives $\mathbf{1 3 8}$ were then submitted under palladium catalysis conditions to undergo 6-endo-trig cyclisation in the presence of allyl bromides, yielding highly substituted cyclohexa[b]indoles 139 (Scheme 30).

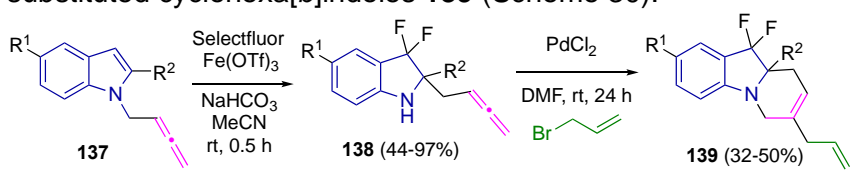

$\mathrm{R}^{1}=\mathrm{Ar}$, alkyl; $\mathrm{R}^{2}=\mathrm{H}, \mathrm{OMe}, \mathrm{F}, \mathrm{NO}_{2}$

Scheme 30. Fe-catalysed domino indole fluorination/allenic aza-Claisen rearrangement followed by $\mathrm{Pd}$-catalysed cyclisation/allylation

In a different approach, Muñoz \& Alonso reported the first tandem process for the platinum catalysed carbocyclisastion/nucleophilic addition of $\mathrm{N}$-indolylallenes $\mathbf{1 4 0}$ with indoles, accessing the challenging 2,3'-bisindolylmethane skeleton 141 (Scheme 31a). ${ }^{73}$ This methodology takes one step forward the gold-catalysed cyclisation of $\mathrm{N}$-indolylallenes, that is not able to undergo the intermolecular nucleophilic addition. However, first investigations showed poor conversions and scope limitations with products 142a and 142b (like 96 obtained under gold catalysis, see Scheme 23) obtained as major or only products when deactivated indoles were used.

Further studies by the same group found that a Au-Pt bimetallic approach efficiently improved both yield and conversion towards the desired structures, and allowed the important extension of the methodology from indolylallenes 140a towards different connectivity such as $\mathbf{1 4 4}$ (and other structures involving pyrroles and metohxybenzenes), and different indoles to give a bigger family of bisindole-products $141 \mathrm{a}$ and 145 (Scheme 31b, c). Interestingly, the reaction also allowed the introduction of other electron-rich aromatics and nitrogen nucleophiles (azoles), showing diverse regioselectivity towards products 143,146 in the latter case (Scheme $31 \mathrm{~b}, \mathrm{c}$ ). ${ }^{74}$ Mechanistic insights suggested bimetallic carbenes 147 as key reaction intermediates for the intermolecular nucleophilic addition step. Detailed investigations into this transformation suggested that the more efficient bimetallic strategy $v s$ the single catalyst methodology was due to synergic cooperation between soluble gold-platinum clusters in equilibrium with heterogeneous gold-platinum particles generated 
in situ, reporting therefore the first example of hybrid homoheterogeneous catalysis in a bimetallic system. ${ }^{75}$

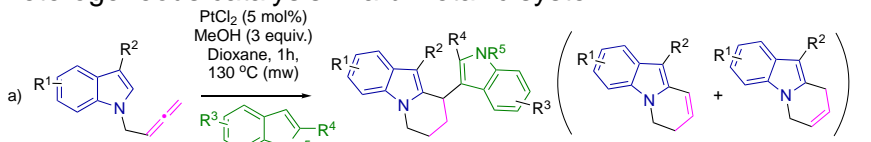

140 $141(10-63 \%)$ 142a: $142 b(5-64 \%)$

$R^{1}=H, M e, O M e, B r ; R^{2}=$ alkyl, aryl; $R^{3}=H, M e, O M e, B r ; R^{4}=H, P h ; R^{5}=H, M e$

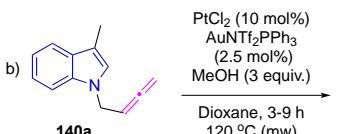

$140 \mathrm{a}$

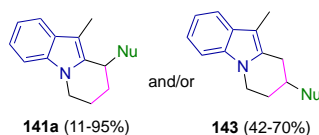

Net = indosen

$\mathrm{NuH}(3$ equiv.)

141a $(11-95 \%)$
with C-NuH
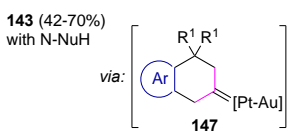

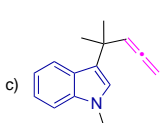

$\mathrm{PtCl}_{2}(10 \mathrm{~mol} \%)$ $\mathrm{ANTf}_{2} \mathrm{PPh}_{3}(2.5 \mathrm{~mol} \%)$

Dioxane, $3-9 \mathrm{~h} 120^{\circ} \mathrm{C}(\mathrm{mw})$

144

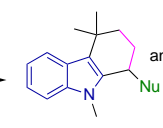

$145(8-95 \%)$
with C-NuH

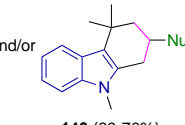

$146(60-70 \%)$
with $\mathrm{N}-\mathrm{NuH}$

Scheme 31. Tandem Au/Pt-catalysed carbocyclisation/nucleophilic addition with indolylallenes and external indoles and other heteroaromatic nucleophiles

Tandem reactions involving untethered indoles and allenes are increasingly appearing in the literature and most of the examples are from the last 3 years. In most of them, the intermolecular reaction occurs first to give intermediates that undergo intramolecular processes.

The classic nucleophilic addition of indoles onto allenes has been further incorporated in a tandem nucleophilic addition/oxycyclisation reaction. Platinum(IV)-catalysed nucleophilic addition of indoles 148 to $\beta$-allenols 149 via Pt-C3-H functionalisation of the indole followed by carbometallation with the allenol yielded indolylallenol intermediate 151. Subsequent oxycyclisation reaction of 151 provided 3-pyranyl-indoles 150, in this case without further involvement of the indole core (Scheme 32). ${ }^{76}$

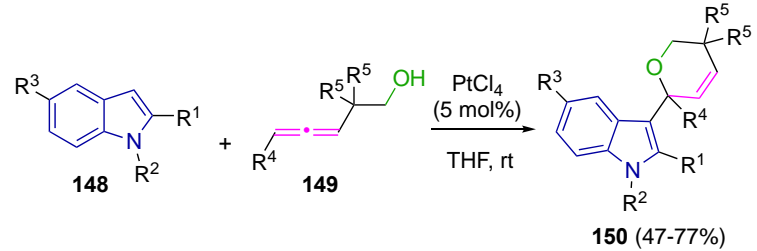

$\mathrm{R}^{1}=\mathrm{H}, \mathrm{Me}, \mathrm{Ph}, \mathrm{Ts}, n \mathrm{Bu} ; \mathrm{R}^{2}=\mathrm{H}, \mathrm{Me} ; \mathrm{R}^{3}=\mathrm{H}, \mathrm{OH}, \mathrm{OBn}, \mathrm{Cl} ; \mathrm{R}^{4}=$ alkyl, $\mathrm{Ph} ; \mathrm{R}^{5}=\mathrm{H}, \mathrm{Me}$<smiles>[Z1]C(=CC([R8])(CO)CO)c1c([R7])n([R7])c2ccc([13CH3])cc12</smiles>

Scheme 32. Pt(IV)-catalysed reaction of indoles and allenols

Swamy reported one of the first examples of C2-functionalised indoles, in which that functionality is involved in the tandem process with an allene, normally substituted with electronwithdrawing groups, as external partner. For example, palladiumcatalysed annulation of indoles 152 bearing C2-carboxylic acids in the presence of allenes yielded indolo[2,3-c]pyrane-1-ones (154, Scheme 33). ${ }^{77}$ Specifically, the reaction of C3-iodo indole derivatives 152a with electron-deficient allenes 153a gave indolopyranones 154a via allyl-palladium intermediates 155 (Scheme 33a). The reaction with simple indoles $152 b$ in the presence of an oxidant goes via $\mathrm{C} 3-\mathrm{H}$ functionalization and formation of palladacycle intermediates 156 (Scheme 33b). Regioselectivity of the addition depends on the electronic properties of the allene.

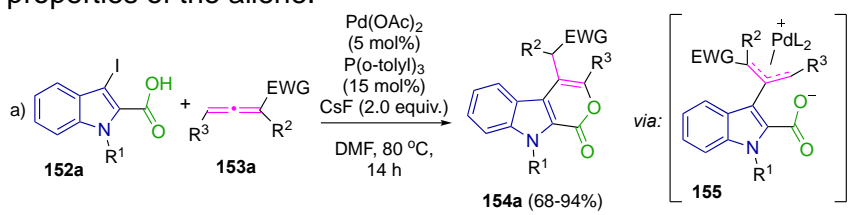

$E W G=P(O)\left(O R_{2}\right), P(O) R_{2}, C O_{2} R, S_{2} R, P h ; R^{1}=M e, B n ; R^{2}=H, A r ; R^{3}=H, M e$

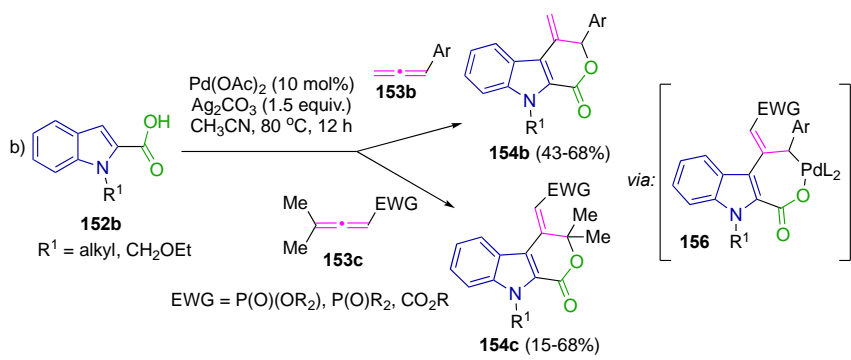

Scheme 33. Pd-catalysed annulation of allenes with indole-2-carboxylic acids

Indolo-2-carbaldehydes 157 have been employed in the phosphine promoted Michael addition to electron-deficient allenes 158 followed by intramolecular Wittig reaction to give $9 \mathrm{H}$ pyrrilo[1,2-a]indole derivatives 159 (Scheme 34). ${ }^{78}$ Activation of the allene by the phosphine occurs similarly to the reactions described in Scheme 3, but in this case, the nitrogen of the indole acts as the nucleophile for the Michael addition to form intermediate 160. Related indolo-2-carbaldehydes have also been employed in the synthesis of pyrrolo[1,2-a]indoles in the presence of allenylphosphonates and allenylsulfones. ${ }^{79}$

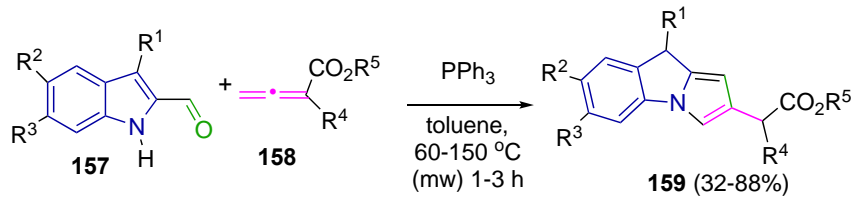

$R^{1}, R^{2}, R^{3}=H, O M e, B r, O B n, M e: R^{4}=H, M e, B n, C_{2} C_{2} E t ; R^{5}=M e, E t$

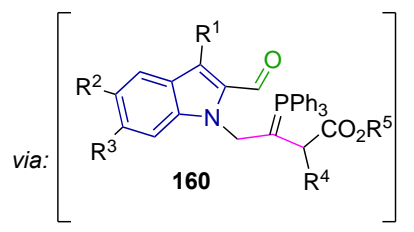

Scheme 34. $\mathrm{Ph}_{3} \mathrm{P}$-promoted reaction of indolo-2-carbaldehydes with allenes

A recent example by Zhou \& Yu and collaborators described the rhodium-catalysed annulative coupling of one indole-2sulfoxonium ylide 161 with allenoate 162 to yield tricyclic structure 163 via rhodium carbenoid intermediate 164 (Scheme 35). ${ }^{80}$ 

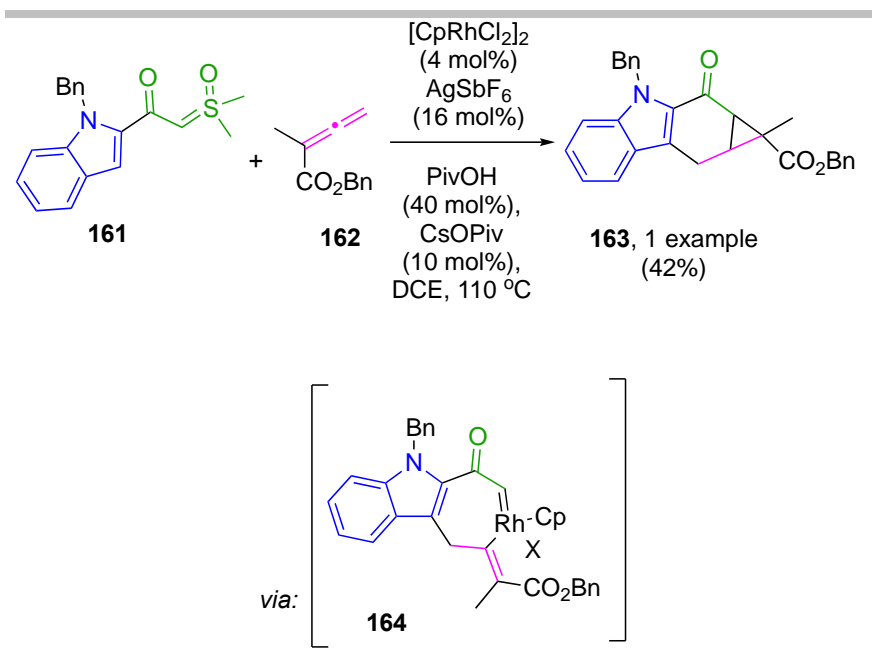

Scheme 35. Rh-catalysed annulative coupling of indole-2-sulfoxonium ylide 161 with allenoate 162

More complex derivatives furoindoles $\mathbf{1 6 5}$ have been reported to engage in gold-catalysed tandem processes with allenamides 166 to give 2-spiroindolin-3-one derivatives 167 (Scheme 36). ${ }^{81}$ The reaction occurs through a cascade sequence involving addition of the $\mathrm{C} 2$-furan to the gold-activated allenamide to give intermediate $\mathbf{1 6 9}$ that undergoes an intramolecular spirocyclisation to give the final compounds 167 in good yields. When the furan does not have a substituent, protodemetalation of 169 can occur to give allylderivatives 168 .

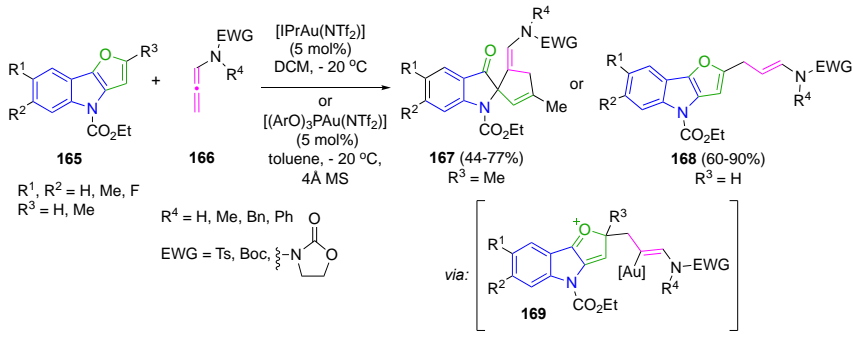

Scheme 36. Au-catalysed reaction of $4 \mathrm{H}$-furo[3,2-b]indoles with allenamides

Recently, an enantioselective route to pyrido[2,3-b]indolines 173 has been described through a de-aromative inter-intramolecular tandem nucleophilic addition of C3-homotryptamine derivatives $170 .^{82}$ These derivatives were reacted with allenamide 171 under chiral Brønsted acid catalysis (172) to generate tetracyclic structures 173 with moderate yields and moderate to excellent ee (Scheme 37). Authors proposed activation of $\mathbf{1 7 0}$ by dual hydrogen bonding with the chiral phosphate with the two N-Hs, as well as formation of an allylphosphate aminal followed by C3nucleohilic attack of the indole to form iminium intermediates 174.

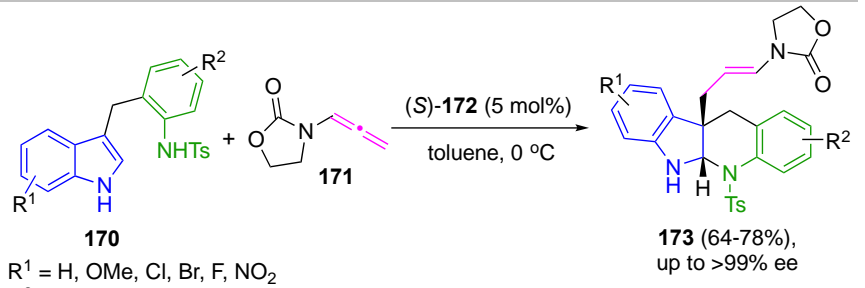
$\mathrm{R}^{1}=\mathrm{H}, \mathrm{OMe}, \mathrm{Cl}, \mathrm{Br}, \mathrm{F}, \mathrm{NO}$
$\mathrm{R}^{2}=\mathrm{H}, \mathrm{Me}, \mathrm{Cl}, \mathrm{Br}, \mathrm{OMe}$

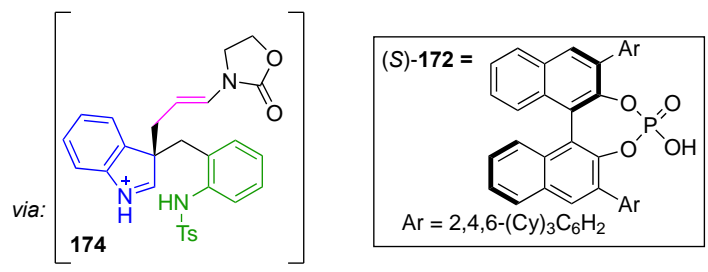

Scheme 37. Acid-catalysed de-aromative cyclisation of homotryptamines with allenamides

Hang \& Jiang have reported the Brønsted acid-catalysed aromatic annulation of alkoxyallenes with naphthols. ${ }^{83}$ In their investigation of the scope, they reported one example from $\mathrm{N}$ protected 4-hydroxyindole 177 and alkoxyallene 178 generating polycyclic compound $\mathbf{1 7 9}$ (Scheme 38 ). The reaction takes place regioselectively in the 4-position of the indole to generate intermediate 180 before cyclisation, debenzoxylation and isomerisation to give $\mathbf{1 7 9}$.

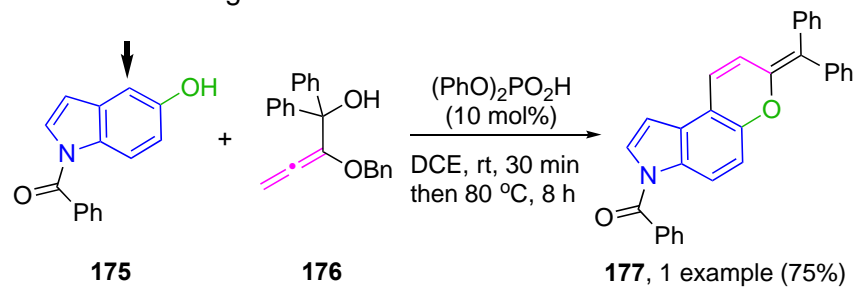<smiles></smiles>

Scheme 38. Acid-catalysed annulation of alkoxyallene 176 with indole 175

Aromatic based allenynes have also been involved in tandem reactions with indoles. For example, the $\mathrm{Fe}$ (III)-catalysed tandem [2+2] cycloaddition of yne-allenones 181 gave intermediates 184 followed by the 1,6-conjugated addition of C3-indoles 182 providing cyclobuta[a]naphthalen-4-ols 183 with all-carbon quaternary centres in good yields (Scheme $39 a$ ). ${ }^{84}$ More recently, the cycloisomerisation reaction of allenynes $\mathbf{1 8 5}$ in the presence of gold catalysis generated vinyl gold cationic intermediates, trapped in situ with a wide range of heterocyclic nucleophiles. When $\mathrm{N}$-deactivated indoles 186 were employed, the heterocyclic moiety behaved as a C2 nucleophile generating carbocationic species 188. Further cyclopropanation and protodeauration steps explained the observed adducts 187 , isolated in good yields (Scheme 39b). ${ }^{85}$ 


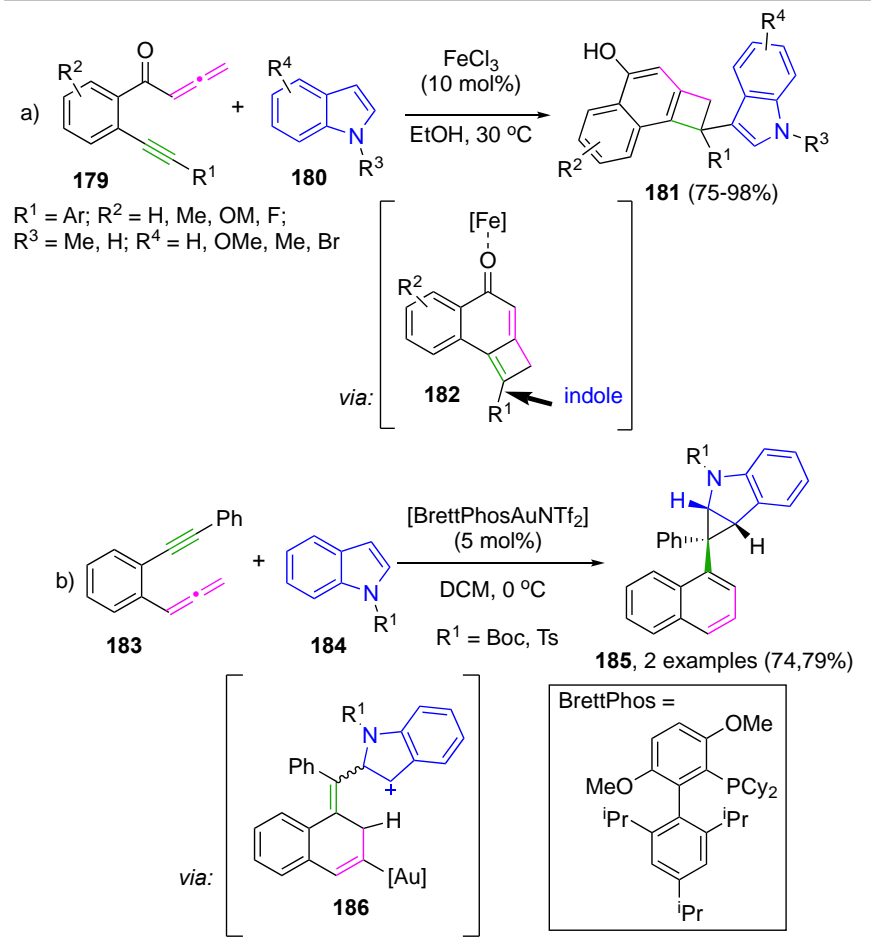

Scheme 39. Metal-catalysed tandem reactions of allenynes with indoles

\subsection{Tandem double intramolecular reactions}

Reactions in which all the components for the tandem reactions are part of the starting material have also been described. These processes give polycyclic structures with increased complexity depending on the connectivity of the different components.

For example, a total synthesis of (+)-lysergic acid has been proposed incorporating a palladium-catalysed allene cyclisation from indolylallenamides 187 as the key step for the generation of the tetracyclic core 188 of this natural product (Scheme 40). ${ }^{86}$ Oxidative addition of the indole- $\mathrm{Br}$ to $\mathrm{Pd}(0)$ and aminopalladation followed by reductive elimination from intermediates 189 would explain the stereoselectiviy observed.

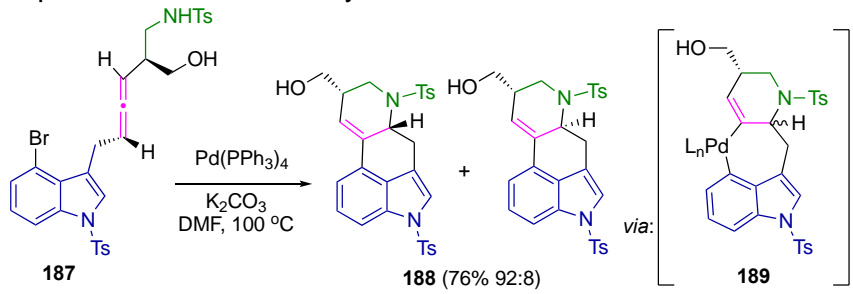

Scheme 40. Key step in the synthesis of (+)-lysergic acid by Pd-catalysed cyclysation of allenes bearing amino and bromoindolyl groups

Shi has described the platinum-catalysed reaction of C3tryptamine-based allenes 190 and other heteroarylallenes of similar structures containing an additional nucleophilic nitrogen, for the construction of complex polycyclic cores. The reactions are proposed to occur by a Friedel-Crafts type annulation of intermediate 191 to give fused polycyclic compounds 192 (Scheme 41 right). ${ }^{87}$ Intermediates 191 can be isolated at lower temperatures $\left(70^{\circ} \mathrm{C}\right)$ and are formed by nucleophilic attack of the -NTs group onto the activated allene followed by migration of the indolylmethylene to form platinum-carbene intermediates. One- pot reaction of more challenging derivatives using the stronger Lewis acid $\mathrm{Sc}(\mathrm{OTf})_{3}$ in the presence pf platinum catalysts, allowed the synthesis of regioisomers 193 (Scheme 41 left).

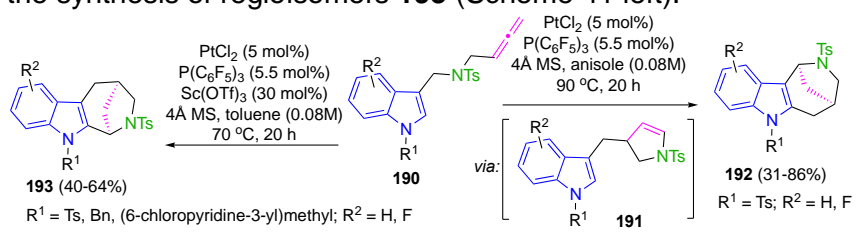

Scheme 41. Pt-catalysed tandem reaction of tryptamine allenes

One of the latest tandem process reported with a more complex starting material is the gold-catalysed cyclopropanation/step-wise [5+3] cycloaddition of heteroaryl containing 1,4-10-allenynes 194 (Scheme 42). The authors reported two examples in which indoles are attached to the alkyne through different positions to give bicyclo[3.3.1]nonane derivatives 196.88 The reaction follows previously reported mechanistic pathways for gold-catalysed cyclisation of enynes via gold carbenes. In this case, intermediates 197 undergoes two sequential cyclopropane ringopening steps to give carbocation species that can be trapped by the indole (or other aromatics) in a Friedel-Crafts-type alkylation.

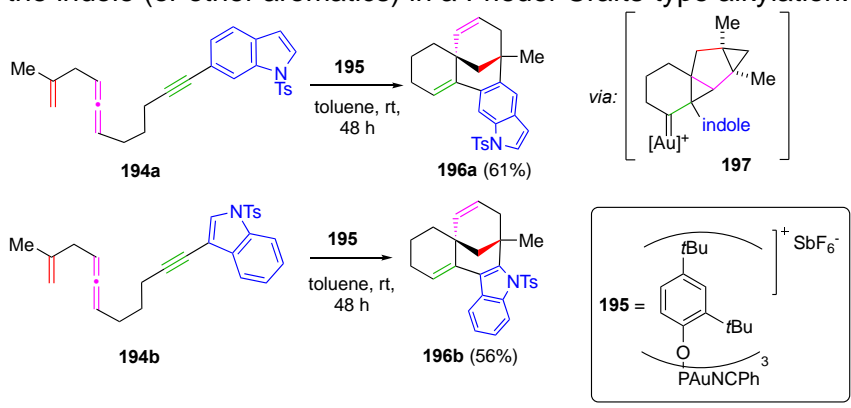

Scheme 42. Au-catalysed synthesis of bicyclo[3.3.1]nonane derivatives

\section{Summary and Outlook}

During the last two decades, allenes and indoles have emerged as a matching couple of reagents for both the synthesis of potentially bioactive compounds, and as adequate substrates for methodological studies. On one hand, a wide number of contributions has appeared describing the preparation of alkaloid scaffolds such as carbazoles, tetrahydrocarbolines, azocines, bis(indolyl)methanes, tropanes, or the total synthesis of natural products such as finderole or lysergic acid. On the other hand, great effort has been made towards the metal-catalysed intermolecular and intramolecular additions of indoles onto allene systems, both in racemic and asymmetric ways, unravelling diverse mechanistic pathways. Recent studies towards more sophisticated mechanistic transformations have also produced the first tandem intra-intermolecular reactions, allowing the synthesis of complex systems in one reaction step, not easily accessible through any other previously known methodology. The continuous advances and contributions in the allene-indole chemistry in the search of more elaborated molecules through more specific transformations, point to new and exciting results shortly coming in this field.

\section{Acknowledgements}


Funding by the University of East Anglia (MPM) and the Universidad Complutense de Madrid (JMA) is gratefully acknowledged.

[1] T. Aniszewski, Alkaloids, Secrets of Life, Chapter 1, Elsevier Science, 2007, p1-59 (ISBN 978-0-444-52736-3).

[2] a) N. Chadha, O. Silakari, Eur. J. Med. Chem. 2017, 134, 159-184; b) E. Stempel, T. Gaich, Acc. Chem. Res. 2016, 49, 2390-2402.

[3] a) L. Chen, Y.-X. Zou, Org.\& Biomol. Chem. 2018, 16, 7544-7556; b) J.S. Lin, T.-T. Liu, J. R. Liu, G.-Y. Jiao, Q.-S. Gu, J.-T. Cheng, X.-Y. Liu, J. Am. Chem. Soc. 2019, 141, 1074-1083; c) A. Maestro, E. Martínez de Marigorta, F. Palacios, J. Vicario, J. Org. Chem. 2019, 84, 1094-1102; d) C.-C. Voll, T. M. Swager, J. Am. Chem. Soc. 2018, 140, 17962-17967; e) S. Nilewar, A. Jayaraman, B. T. Sterenberg, Organometallics 2018 37, 4699-4710; f) M. Bandini, A. Eichholzer, Angew. Chem. Int. Ed. 2009 , $48,9608-9644 ;$ g) B. S. Lane, M. A. Brown, D. Sames, J. Am. Chem. Soc 2005, 127, 8050-8057; h) M. Cotella, L. Degennaro, R. Luisi, Molecules 2020, 25, 3242-3268; i) P. Milcendeau, N. Sabat, A. Ferry, X. Guinchard Org. \& Biomol. Chem. 2020, 18, 6006-6017; S. Taliani, F. De Settimo, C. Martini, S. Laneri, E. Nvellino, G. Greco, Molecules, 2020, 25, 2331 2358; j) K. Kaur, V. Jaitak, Anti-Cancer Agents in Med. Chem. 2020, 19 962-983; k) G. Bartoli, G. Bencivenni, R. Dalpozzo, Chem. Soc. Rev. 2010, 39, 4449-4465; I) R. Dalpozzo, Chem. Soc. Rev. 2015, 44, 742 778.

[4] a) Y. Shichao, S. Ma, Angew. Chem. Int. Ed. 2012, 51, 3074-3112; b) B. Alcaide, P. Almendros, C. Aragoncillo, Chem. Soc. Rev. 2014, 43, 31063135; c) S. Yu, S. Ma, Angew. Chem, Int. Ed. 2012, 51, 3074-3112; d) V. Schmiedel, H.-U. Reissig, Curr. Org. Chem. 2019, 23, 2976-3003; e) R. J. Armstrong, Curr. Org. Chem. 2019, 23, 3027-3039; f) L. Liu, R. M. Ward, J. M. Schomaker, Chem. Rev. 2019, 119, 12422-12490; g) G. Li, X. Huo, X. Jiang, W. Zhang, Chem. Soc. Rev. 2020, 49, 2060-2118; h) S. Ma, Chem. Rev. 2005, 105, 7, 2829-2872.

[5] For recent reviews, see: a) E. M. Beccalli, G. Broggini, M. S. Christodoulou, S. Giofre. Adv. Organometallic Chem. 2018, 69, 1-71; b) J. L. Mascareñas, I. Varela, F. López, Acc. Chem, Res. 2019, 52, 465 479; c) R. Santhoshkumar, C.-H. Cheng, Asian J. Org. Chem. 2018, 7 1151-1163; d) J. M. Alonso, M. T. Quirós, M. P. Muñoz, Org. Chem. Front 2016, 3, 1186-1204; e) H.-M. Huang, P. Bellotti, F. Glorius, Chem. Soc. Rev. 2020, 49, 6186-6197; f) B. M. Trost, J. S. Tracy, Acc. Chem. Res. 2020, 53, 1568-1579; g) A. L. Cardoso, M. I. L. Soares, Curr. Org. Chem. 2019, 23, 3064-3134; h) E.-Q. Li, Y. Huang, Chem. Commun. 2020, 56, 680-694; i) R. W. Bates, V. Satcharoen, Chem. Soc. Rev. 2002, 31, 12 21.

[6] For selected examples, see: a) A. A. Festa, R. R. Zalte, N. E. Golantsov, A. V. Varlamov, E. V. Vander Eycken, L. G. Voskressensky, J. Org. Chem. 2018, 83, 9305-9311; b) M. Taguchi, Y. Tokimizu, S. Oishi, N Fujii, H. Ohno, Org. Lett. 2015, 17, 6250-6253; c) D. Uredi, D. Reddy Motati, E. Blake Watkins, Org. Lett. 2018, 20, 6336-6339; d) Y. Xu, G. Zheng, L. Kong, X. Li, Org. Lett. 2019, 21, 3402-3406; e) K. Selvaraj, S. Debnath, K. C. Kumara Swamy, Org. Lett. 2019, 21, 5447-5451; f) C. R Reddy, M. Subbarao, P. Satish, D. H. Kolgave, R. Reddy Donthiri, Org. Lett. 2020, 22, 689-693; g) G. Cera, N. Della Ca', G. Maestri, Chem. Sci. 2019, 10, 10297-10303; h) J. Hédouin, C. Schneider, I. Gillaizeau, C Hoarau, Org. Lett. 2018, 20, 6027-6032; i) S. Pradhan, C. K. Shahi, A Bhattacharyya, M. K. Ghorai, Chem. Commun. 2018, 54, 8583-8586; j) N. Iqbal, C. A. Sperger, A. Fiksdahl, Eur. J. Org. Chem. 2013, 907-914 k) L. Zhang, Y. Zhu, G. Yin, P. Lu, Y. Wang, J. Org. Chem. 2012, 77 9510-9520; I) G. Cera, M. Lanzi, D. Balestru, N. Della Ca', R. Maggi, F. Bigi, M. Malacria, G. Maestri, Org. Lett. 2018, 20, 3220-3224; m) S Wang, Z. Chai, Y. Wei, X. Zhu, S. Zhou, S. Wang, Org. Lett. 2014, 16, 3592-3595; n) M. Patel, Sushmita, A. K. Verma, J. Chem. Sci. 2018 130:70; o) K. Selvaraj, K. C. K. Swamy, J. Org. Chem. 2018, 83, 1504315056.

[7] For selected examples, see: a) A. Voituriez, N. Pinto, M. Neel, P. Retailleu, A. Marinetti, Chem. Eur. J. 2010, 16, 12541-12544; b) C. Gomez, M. Gicquel, J.-C. Carry, L. Schio, P. Retailleau, A. Voituriez, A. Marinetti, J. Org. Chem. 2013, 78, 1488-1496; c) X.-Y. Wu, Y.-N. Gao, M. Shi, Eur. J. Org. Chem. 2019, 1620-1626; d) F. Wang, Z. Li, J. Wang, X. Li, J.-P. Cheng, J. Org. Chem. 2015, 80, 5279-5286; e) M. Gicquel, C.
Keywords: allenes $•$ indoles $\bullet$ transition metal $•$ catalysis $•$

polycyclic structures

Gomez, P. Retailleau, A. Voituriez, A. Marinetti, Org. Lett. 2013, 15, 4002-4005; f) H. Ni, X. Tang, W. Zheng, W. Yao, N. Ullah, Y. Lu, Angew. Chem. Int. Ed. 2017, 56, 14222-14226; g) H. A. Dondas, A. Hempshall, S. Narramore, C. Kilner, C. W.G. Fishwick, R. Crigg, Tetrahedron 2016, 72, 1316-1329; h) Z. Tang, Z. Liu, Y. An, R. Jiang, X. Zhang, C. Li, X. Jia J. Li, J. Org. Chem. 2016, 81, 9158-9166; i) S. Li, Z. Tang, Y. Wang, D. Wang, Z. Wang, C. Yu, T. Li, D. Wei, C. Yao, Org. Lett. 2019, 21, 1306 1310; j) G. Wang, X. Liu, Y. Chen, J. Yang, J. Li, L. Lin, X. Feng, ACS Catal. 2016, 6, 2482-2486; I) J. Chen, Y. Cai, G. Zhao, Adv. Synth. Catal. 2014, 356, 359-363; m) K. M. Brummond, J. R. Goodell, M. G. LaProte, L. Wang, X.-Q. Xie, Belsteins, J. Org. Chem. 2012, 8, 1048-1058; n) C Ni, Y. Zhang, Y. Hou, X. Tong, Chem. Commun. 2017, 53, 2567-2570; o) D.-H. Zhang, M. Shi, ChemistryOpen 2012, 1, 215-220; p) B. M. Trost J. Xie, J. D. Sieber, J. Am. Chem. Soc. 2011, 133, 20611-20622; q) C.S. Wang, R.-Y. Zhu, J. Zheng, F. Shi, S.-J. Tu, J. Org. Chem. 2015, 80, 512-520; E. Li, Y. Huang, L. Liang, P. Xie, Org. Lett. 2013, 15, 3138 3141; T. Wang, W. Yao, F. Zhong, G. H. Pang, Y. Lu, Angew. Chem. Int. Ed. 2014, 53, 2964-2968.

[8] For selected examples, see: a) V. Gobé, M. Dousset, P. Retailleau, V. Gandon, X. Guinchard, J. Org. Chem. 2018, 83, 898-912; b) V. Gobé, X. Guinchard, Chem. Eur. J. 2015, 21, 8511-8520, c) Gobé, M. Dousset, P. Retailleau, V. Gandon, X. Guinchard, Adv. Synth. Catal. 2016, 358, 3960-3965; d) V. Gobé, X. Guinchard, Org. Lett. 2014, 16, 1924-1927.

[9] For selected examples, see: a) C. Li, Z. Yang, L. Wang, Y. Guo, Z. Huang, S. Ma, Angew. Chem Int. Ed. 2020, 59, 6278-6283; b) O. A. Storozhenko, A. A. Festa, G. I. Detistova, V. B. Rybakov, A. V. Varlamov, E. V. Van der Eycken, L. G. Voskressensky, J. Org. Chem. 2020, 85, 2250-2259; c) D. Berthold, B. Breit, Org. Lett. 2020, 22, 565-568.

[10] a) M. Jia, M. Monari, Q. Yang, M. Bandini, Chem. Commun. 2015, 51, 2320-2323; b) R. Ocello, A. de Nisi, M. Lia, Q. Yang, M. Monari, P. Giacinto, A. Bottoni, G. P. Miscione, M. Bandini, Chem. Eur. J. 2015, 21, 18445-18453; c) E. Manoni, A. de Nisi, M. Bandini, Pure Appl. Chem. 2016, 88, 207-214.

[11] a) V. Pirovano, L. Decataldo, E. Rossi, R. Vicente, Chem. Commun 2013, 49, 3594-3596. b) V. Pirovano, M. Borri, G. Abbiati, S. Rizzato, E. Rossi. Adv. Synth. Catal. 2017, 359, 1912-1918.

[12] Y. Wang, P. Zhang, Y. Liu, F. Xia, J. Zhang, Chem. Sci, 2015, 6, 55645570 .

[13] H. Hu, Y. Wang, D. Qian, Z.-M. Zhang, L. Liu, J. Zhang, Org. Chem. Front. 2016, 3, 759-763.

[14] a) L.-W. Jin, F. Jiang, K.-W. Chen, B.-X. Du, G.-J. Mei, F. Shi, Org Biomol. Chem. 2019, 17, 3894-3901; b) K. Liu, G. Wang, S.-J. Cheng, W.-F. Jiang, C. He, Z.-S. Ye, Tet. Lett. 2019, 60, 1885-1890; c) L. Birbaum, L. Gillard, H. Gérard, H. Oulyadi, G. Vincent, X. Moreau, M. De Paolis, I. Chataigner, Chem. Eur. J. 2019, 25, 13688-13693; For a gramscale protocol on this transformation, see: d) A. Cerveri, O. Nieto Faza, C. Silva López, S. Grilli, M. Monari, M. Bandini, J. Org. Chem. 2019, 84, 6347-6355; e) H. Wang, J. Zhang, Y. Tu, J. Zhang, Angew. Chem. Int. Ed. 2019, 58, 5422-5426; f) K. Li, T. P. Gonçalves, K.-W. Huang, Y. Lu Angew. Chem. Int. Ed. 2019, 58, 5427-5431.

[15] For examples of [3+2] see: b) L. Cai, K. Zhang, O. Kwon, J. Am. Chem Soc. 2016, 138, 3298-3301; c) I. P. Andrews, O. Kwon, Chem. Sci. 2012, 3, 2510-2514. For examples of [4+2], see: d) R. A. Villa, Q. Xu, O. Kwon, Org. Lett. 2012, 14, 4634-4637; e) Y. S. Tran, O. Kwon, Org. Lett. 2005, 7, 4289-4291

[16] K. L. Toups, G. T. Liu, R. A. Widenhoefer, J. Organomet. Chem. 2009, $694,571-575$

[17] M.-Z. Wang, C.-Y. Zhou, Z. Guo, E. L.-M. Wong, M.-K. Wong, C.-M. Che, Chem. Asian J. 2011, 6, 812-824.

[18] D. R. Sutherland, L. Kinsman, S. M. Angiolini, G. M. Rosair, A.-L. Lee, Chem. Eur. J. 2018, 24, 7002-7009.

[19] C. N. Kona, M. H. Shinde, C. V. Ramana, Org. Biomol. Chem. 2015, 13, 5358-5362.

[20] H. Li, T. Ma, Z. Zhao, RSC Adv. 2015, 5, 84044-84047. 
[21] H. Li, X. Li, Z. Zhao, T. Ma, C. Sun, B. Yang, Chem. Coummun. 2016, 52, 10167-10170.

[22] M. Jia, G. Cera, D. Perrota, M. Monari, M. Bandini, Chem. Eur. J. 2014, 20, 9875-9878.

[23] L. Rocchigiani, M. Jia, M. Bandini, A. Macchioni, ACS Catal. 2015, 5, 3911-3915.

[24] P. Giacinto, A. Bottoni, A. Garelli, G. P. Miscione, M. Bandini, ChemCatChem 2018, 10, 2442-2449.

[25] R.-D. Gao, Y. Zhai, S.-L. You, S. Ma, Org. Chem. Front. 2018, 5, 16641669.

[26] Y. Zhai, S.-L. You, S. Ma, Org. Biomol. Chem. 2019, 17, 7128-7130.

[27] a) D. K. Sharma, A. K. Tripathi, R. Sharma, R. Chib, R. Rasool, A. Hussain, B. Singh, A. Goswami, I. A. Khan, D. Mukherjee, Med. Chem. Res. 2014, 23, 1643-1653; b) B. Song, X. Qu, L. Zhang, K. Han, D. Wu, C. Xiang, H. Wu, T. Wang, Y. Teng, P. Yu,. J. Chem. Pharm. Res. 2014 6, 239-243; c) C. Grosso, A. L. Cardoso, A. Lemos, J. Varela, M. J. Rodrigues, L. Custodio, L. Barreira, T. M. V. D. Pinho e Melo, Eur. J. Med. Chem. 2015, 93, 9-15; d) S. Imran, M. Taha, N. H. Ismail, Curr. Med. Chem. 2015, 22, 4412-4433; e) E. B. McLean, F. M. Cutolo, O. J. Cassidy, D. J. Burns, A.-L. Lee, Org. Lett. 2020, 22, 6977-6981.

[28] S. Ma, S. Yu, Org. Lett. 2005, 7, 5063-5065.

[29] M. P. Muñoz, M. C. Torre, M. A. Sierra, Chem. Eur. J. 2012, 18, 44994505.

[30] J. Barluenga, M. Piedrafita, A. Ballesteros, A. L. Suarez-Sobrino, J. M. Gonzalez, Chem. Eur. J. 2010, 16, 11827-11831.

[31] C. Wang, A. Wang, M. Ruepig, Angew. Chem. Int. Ed. 2017, 56, 99359938.

[32] S.-Y. Chen, X.-L. Han, J.-Q. Wu, Q. Li, Y. Chen, H. Wang, Angew. Chem. Int. Ed. 2017, 56, 9939-9943.

[33] X. Ma, Y. Dang, J. Org. Chem. 2019, 84, 1916-1924.

[34] S. Nakanowatari, R. Mei, M. Feldt, L. Acermann, ACS Catal. 2017, 7, 2511-2515.

[35] S. Li, X.-X. Wu, S. Chen, Org. Biomol. Chem. 2019, 17, 789-793.

[36] S. H. Jang, H. Woo, Kim, W. Jeong, D. Moon, Y. H. Rhee, Org. Lett. 2018 , 20, 1248-1251.

[37] a) C. Ferrer, A. M. Echavarren, Angew. Chem. Int. Ed. 2006, 45, 11051109; b) Q. Lu, S. Gressies, F. J. R. Klauck, F. Glorius, Angew. Chem. Int. Ed., 2017, 56, 6660-6664.

[38] a) L.-Y. Mei, Y. Wei, X.-Y. Tang, M. Shi, J. Am. Chem. Soc. 2015, 137, 8131-8137. For recent computational studies, see: R. Fang, Z. Feng, A. M. Kirillov, L. Yang, Organomet. 2020, 39, 1782-1789.

[39] Y.-Y. Zhang, Y. Wei, M. Shi, Chem. Commun. 2019, 55, 4210-4213.

[40] Y.-Y. Zhang, Y. Wei, M. Shi, Org. Lett. 2019, 21, 8250-8255.

[41] a) N. Arai, T. Ohkuma, Org. Lett. 2019, 21, 1506-1510; b) N. Arai, T. Ohkuma, Tetrahedron Lett. 2019, 60, 151252-151255.

[42] V. Magné, Y. Sanogo, C. S. Demmer, P. Retailleau, A. Marinetti, X. Guinchard, A. Voituriez, ACS Catal. 2020, 10, 8141-8148.

[43] Z. Zhang, C. Liu, R. E. Kinder, X. Han, H. Qian, R. A. Widenhoefer, J. Am. Chem. Soc. 2006, 128, 9066-9073.

[44] a) N. Kato, E. Comer, T. Sakata-Kato. Nature 2016, 538, 344; b) N. G. Pacaroni, R. Ratnayake, J. H. Matthews, V. M. Morwood IV, A. C. Arnold, L. H. Dang, H. Luesch, H. Huigens III, Chem. Eur. J. 2017, 23, 44634463; c) C.-X. Zhuo, Q.-F. Wu, Q. Zhao, Q.-L. Xu, S.-L. You, J. Am. Chem. Soc. 2013, 135, 8169-8172; d) J. Stöckigt, A. P. Antonchick, F. Wu, H. Waldmann, Angew. Chem. Int. Ed. 2011, 50, 8538-8564.

[45] a) J. S. Stehouwer, Current Topics in Medicinal Chemistry, 2013, 13, 920-935; b) J. Jeenu, J. Lincy, G. Mathew, World J. Pharm. Res. 2016 5, 353-367; c) K. Walton, J. P. Berry, Marine Drugs, 2016, 14, 73/173/28; d) V. Bhat, A. Dave, J. A. MacKay, V. H. Rawal, Alkaloids Chem. Biol, 2014, 73, 65-160.

[46] C. Liu, R. A. Widenhoefer, Org. Lett. 2007, 9, 1935-1938.

[47] a) K. B. Balasaheb, P. S. Rao, S. S. Siddheshwar, World J. Pharm. Res. 2019, 8, 290-296; b) R. G. Zenlov, L. V. Ektova, O. A. Vlasova, G. A. Belistkiy, M. G. Yakubovskaya, K. I. Kirsanov, Chemistry of Heterocyclic Compounds, 2020, 56, 644-658; b) H.- J. Knöller, K. R. Reddy, Chemistry and Biology of Carbazole, in the Alkaloids, (Ed.: G. A. Cordell), Academic Press, Amsterdam, Vol. 65, 2008, pp 1-430.

[48] a) W. Kong, C. Fu, S. Ma, Org. Biomol. Chem. 2012, 10, 2164-2173; b) W. Kong, C. Fu, S. Ma, Chem. Commun. 2009, 4572-4574.

[49] B. Alcaide, P. Almendros, J. M. Alonso, M. T. Quirós, P. Gadzinski, Adv. Synth. Catal. 2011, 353, 1871-1876.
[50] W. Kong, C. Fu, S. Ma, Chem. Eur. J. 2011, 17, 13134-13137;

[51] a) Y. Qiu, X. Zhang, C. Fu, S. Ma, Chem. Eur. J. 2014, 20, 10314-10322; b) W. Kong, Y. Qiu, X. Zhang, C. Fu, S. Ma, Adv. Synth. Catal. 2012, 354, 2339-2347.

[52] For a computational study, see: M. G. Menkir, S. L. Lee, ChemistrySelect 2018, 3, 12093-12107.

[53] B. Alcaide, P. Almendros, J. M. Alonso, S. Cembellin, I. Fernandez, T. Martinez del Campo, M. R. Torres, Chem. Commun. 2013, 49, 7779 7781.

[54] B. Alcaide, P. Almendros, J. M. Alonso, I. Fernandez, S. Khodabakhshi, Adv. Synth. Catal. 2014, 356, 1370-1374.

[55] B. Alcaide, P. Almendros, S. Cembellin, T. Martínez del Campo. J. Org. Chem. 2015, 80, 4650-4660.

[56] a) M. Emanuela, G. Casamassima, S. Castiglione, E. Cellupica, S. Pantalone, F. Papagani, M. Rui, A. M. Siciliano, S. Colina, Bioorg. \& Med Chem. Lett. 2018, 28, 2816-2826; b) A. Keglevich, S. Mayer, R. Papai, A. Szigetvari, Z. Santa, M. Dekany, P. Keglevich, L. Hazai. Molecules, 2018, 23, 2574-2595; c) Y. Zhang, S.-H. Yang, X.-L. Guo, Biomedecine \& Pharmacology, 2017, 96, 659-666.

[57] R. M. Zeldin, F. D. Toste. Chem. Sci. 2011, 2, 1706-1709.

[58] C. Grandclaudon, V. Michelet, P. Y. Toullec, Synlett 2018, 310-313.

[59] Y. Wang, P. Zhang, X. Di, Q. Dai, Z.-M. Zhang, J. Zhang, Angew. Chem. Int. Ed. 2017, 56, 15905-15909.

[60] V. Magné, F. Blanchard, A. Marinetti, A. Voituriez, X. Guinchard. Adv. Synth. Catal. 2016, 358, 3355-3361.

[61] C. P. Grugel, B. Breit, Org. Lett. 2019, 21, 5798-5802.

[62] C. P. Grugel, B. Breit, Org. Lett. 2019, 21, 9672-9676.

[63] E. Alvarez, P. Garcia-Garcia, M. A. Fernandez-Rodriguez, R. Sanz, J. Org. Chem. 2013, 78, 9758-9771

[64] B. Guo, X. Huang, C. Fu, S. Ma, Chem. Eur. J. 2016, 22, 18343-18348.

[65] A. Luna, F. Herrera, S. Higuera, A. Murillo, I. Fernández, P. Almendros, J. Catal. 2020, 389, 432-439.

[66] B. Alcaide, P. Almendros, J. M. Alonso, I. Fernandez, J. Org. Chem. 2013, 78, 6688-6701.

[67] B. Chen, W. Fan, G. Chal, S. Ma, Org. Lett. 2012, 14, 3616-3619.

[68] B. Yuan, R. He, X. Guo, W. Shen, F. Zhang, Y. Xu, M. Li, New J. Chem. 2018, 42, 15618-15628.

[69] E. M. Beccalli, A. Bernasconi, E. Borsini, G. Broggini, M. Rigamonti, G. Zecchi, J. Org. Chem. 2010, 75, 6923-6932.

[70] D. Ivanova, H. Gronemeyer, A. R. de Lera, ChemMedChem 2011, 6, 1518-1529.

[71] B. Alcaide, P. Almendros, J. M. Alonso, I. Fernández. Chem. Commun. 2012, 48, 6604-6606.

[72] B. Alcaide, P. Almendros, S. Cembellin, T. Martinez del Campo, A Muñoz, Chem, Commun. 2016, 52, 6813-6816.

[73] L. Cooper, J. M. Alonso, L. Eagling, H. Newson, S. Herath, C. Thomson, A. Lister, C. Howsham, B. Cox, M. P. Muñoz. Chem. Eur. J. 2018, 24, 6105-6114.

[74] J. M. Alonso, M. P. Muñoz, Angew. Chem. Int. Ed. 2018, 57, 4742-4746.

[75] J. M. Alonso, M. P. Muñoz, ChemCatChem 2018, 10, 2646-2654.

[76] W. Kong, J. Cui, Y. Yu, G. Chen, C. Fu, S. Ma, Org. Lett. 2009, 11, 12131216.

[77] R. Rama, Suresh, K. C. K. Swamy, J. Org. Chem. 2012, 77, 6959-6969.

[78] C. Lorton, A. Voituriez, J. Org. Chem. 2018, 83, 5801-5806.

[79] M. P. Pavan, K. C. K. Swamy, Synlett 2011, 9, 1288-1299.

[80] J. Lou, Q. Wang, Y.-G. Zhou, Z. Yu, Org. Lett. 2019, 21, 9217-9222.

[81] V. Pirovano, E. Brambilla, S. Rizzato, G. Abbiati, M. Bozzi, E. Rossi, J. Org. Chem. 2019, 84, 5150-5166.

[82] S. Biswas, H. Kim, K. L. A. Cao, S. Shina. Adv. Synth. Catal. 2020, 362 1841-1845.

[83] J. Zhang, L. Zhu, K. Shen, H. Yang, X.-C. Hang, G. Jiang, Chem. Sci. 2019, 10, 1070-1074.

[84] H. Li, W.-J. Hao, G. Li, S.-J. Tu, B. Jiang, Front. Chem. 2018, 6:599.

[85] T. Ikeuchi, S. Inuki, S. Oishi, H. Ohno. Angew. Chem. Int. Ed. 2019, 58, 7792-7796.

[86] S. Inuki, A. Iwata, S. Oishi, N. Fujii, H. Ohno, J. Org. Chem. 2011, 76, 2072-2083.

[87] Y.-Y. Zhang, Y. Wei, X.-Y. Tang, M. Shi, Chem. Commun. 2017, 53, 5966-5969.

[88] X. Chen, Y. Zhou, J. Jin, K. Farshadfar, A. Ariafrad, W. Rao, P. W. H. Chan, Adv. Synth. Catal. 2020, 362, 1084-1095. 


\section{Entry for the Table of Contents}

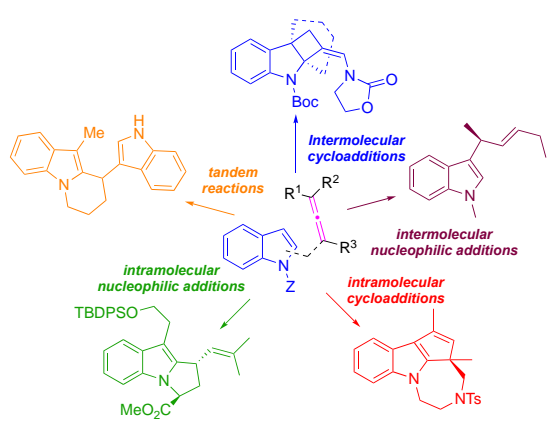

Key Topic: indole-allene reactivity

This minireview follows the story from the time when indole and allene first met in a metal catalysed nucleophilic addition in the second half of the 2000's, through 15 years of encounters under diverse reaction conditions, in which a fruitful relationship has allowed the synthesis of more complex products and revealed new exciting mechanistic pathways. 